\title{
Development of a High-Resolution Multiscale Modeling and Prediction System for Bay of Bengal, Part II: An Application to October 2008
}

\author{
Arun Chakraborty ${ }^{*}$, Avijit Gangopadhyay ${ }^{1,2,3}$ \\ ${ }^{1}$ Centre for Oceans, Rivers, Atmosphere and Land Sciences (CORAL), Indian Institute of Technology Kharagpur, \\ Kharagpur, India \\ ${ }^{2}$ School of Earth, Ocean and Climate Sciences, Indian Institute of Technology Bhubaneswar, Bhubaneswar, India \\ ${ }^{3}$ School for Marine Science and Technology, University of Massachusetts, Dartmouth, USA \\ Email: "arunc@coral.iitkgp.ernet.in, agangopadhya@umassd.edu
}

Received 2 December 2015; accepted 26 January 2016; published 29 January 2016

Copyright $@ 2016$ by authors and Scientific Research Publishing Inc.

This work is licensed under the Creative Commons Attribution International License (CC BY). http://creativecommons.org/licenses/by/4.0/

(c) (i) 0pen Access

\section{Abstract}

A high-resolution $(10 \mathrm{~km} \times 10 \mathrm{~km})$ multiscale ocean modeling system was developed for the Bay of Bengal (BOB) region for short-term ocean hindcasts/forecasts. A physical validation of this system that was based on climatological initialization and short-term simulations was presented in Part I of this series of studies. Realistic structures for prevalent eddies, fronts and gyres were reasonably reproduced and validated for three individual months (February, June and October). In this study, we present an application and synoptic validation of the system for October 2008 in a hindcast mode. The system is based on the Regional Ocean Modeling System (ROMS), which assimilates satellite and in-situ measurements within the background climatology using an objective analysis to produce the synoptic initial condition for the model and/or to produce an estimation of the current ocean state. A meteorological forecast is then input into this synoptic three-dimensional ocean model to produce the ocean hindcast/forecast. The high-density Array for Real-time Geotropic Oceanography (ARGO) observations, and the Tropical Rain Measuring Mission (TRMM) satellite's microwave imager (TMI) passes during the beginning of the month of October 2008, provided a unique opportunity for the system to assimilate these in-situ observations at initialization. Then, the ARGO and TMI observations during the later part of October 2008 were used for the statistical validation of the system's fidelity. The validation shows that the hindcast/forecast system can reasonably predict the ocean currents, temperature and salinity. The forecast error increases as the forecast time window increases, although the system has a reasonable predictability for up to seven to ten days. The assimilation of both in-situ ARGO and satellite data at initialization pro*Corresponding author. 
duced better hindcasts/forecasts.

Keywords

ARGO, TMI, ROMS, Simulation

\section{Introduction}

Operational ocean forecast models are now available on all scales, from global to local. Typically, such models are initialized by climatological data when needed or, if the direct measurements of oceanic parameters are available for the region of interest, by melding climatology with observations. For applications in fisheries management and for naval operations, fine-resolution ocean forecasts are frequently required for limited regions.

The Bay of Bengal is a land-locked region (Figure 1(a)) with a semi-annually reversing wind system that causes a semi-annually reversing surface circulation. Severe tropical cyclones that are generated during the spring (April-May) and fall (October) cause large-scale flooding and destruction along the coast; such a region requires a forecasting system. However, because of the scarcity of in-situ data, many mesoscale features are not well understood, and no prediction system is available for this region. Thus, for the first time, a high-resolution multiscale ocean prediction system was developed using ROMS [1] [2] for the BOB basin (Figure 1(b)). This ocean forecasting system is intended to produce a daily, short-term (one week to ten day) forecast of the mesoscale ocean current, temperature, salinity and sea-level variation.

The first step in generating a prediction system is to validate the system and to develop phenomenological features in a realistic manner. The shapes, sizes and occurrences of major features should be reproduced in a realistic and statistical manner. In our Part I paper [3], we discussed different multiscale features from climatology-based simulations over a 30-day period for three periods: February for winter, June for summer, and October for fall.

To make the forecasts as close as possible to reality, the models are driven by synoptic atmospheric forcing fields and by the assimilation of real-time observations, which may consist of remotely sensed data and in-situ measurements. We conducted experiments to assess the forecast capability by assimilating TMI and ARGO data sets for October 4-6, 2008 with Levitus $0.25^{\circ} \times 0.25^{\circ}$ climatology [4] [5] and by applying surface forcing. The prediction system methodology and comparison of the ocean hindcasts/forecasts to the synoptic simulation are discussed in detail in this paper. Section 2 describes the prevalent features in October; Section 3 describes the TMI and ARGO data sets and model domain; Section 4 describes the experimental setup; Section 5 provides the evolution of the synoptic simulation and validation; and Section 6 provides the summary and conclusions.

\section{Prevalent Features in the BOB Region during October}

A schematic presentation of the oceanographic features in the BOB region during October is shown in Figure 2. This representation is required to validate the regional oceanographic features with respect to the model simulations. A list of relevant studies that were used to identify the features is provided in Table 1. In October, the northeast monsoon has just started, and the surface circulation is dominated by a basin-scale cyclonic gyre (CG) with mesoscale anticyclonic eddies (AE) at $91^{\circ} \mathrm{E}, 21^{\circ} \mathrm{N}$ and $93^{\circ} \mathrm{E}, 18^{\circ} \mathrm{N}$ and cyclonic eddies (CE) at $97^{\circ} \mathrm{E}, 16^{\circ} \mathrm{N}$; $95^{\circ} \mathrm{E}, 10^{\circ} \mathrm{N} ; 83^{\circ} \mathrm{E}, 11^{\circ} \mathrm{N} ; 83^{\circ} \mathrm{E}, 13^{\circ} \mathrm{N}$; and $91^{\circ} \mathrm{E}, 12.5^{\circ} \mathrm{N}$. The surface circulation shows a well-defined boundary current along the Indian coast, known as the East India Coastal Current (EICC), which moves toward the equator [6]. The Indian Ocean water enters the BOB at around $90^{\circ} \mathrm{E}$. During October, warm water enters the Andaman Sea through the Malacca Strait and may originate from the South China Sea [6].

There is also surface flow from the Bay of Bengal to the Arabian Sea via the Palk Strait. A similar flow from the BOB to the Arabian Sea is also reported through geostrophic currents [7], ship-drift currents [6], direct current measurements [8] and model analysis [9]. The EICC bifurcates at the northern tip of Sri Lanka. One branch passes along the eastern coast of Sri Lanka and moves eastward around $8^{\circ} \mathrm{N}$, as does the North Equatorial Current (NEC), and the other branch passes through the Palk Strait. The Palk Strait flow again bifurcates, with one branch flowing to the Arabian Sea, and the other moving eastward along the southern Sri Lankan coast. The NEC moves northward and joins with the flow from the Malacca Strait at the northern side of Andaman Island 


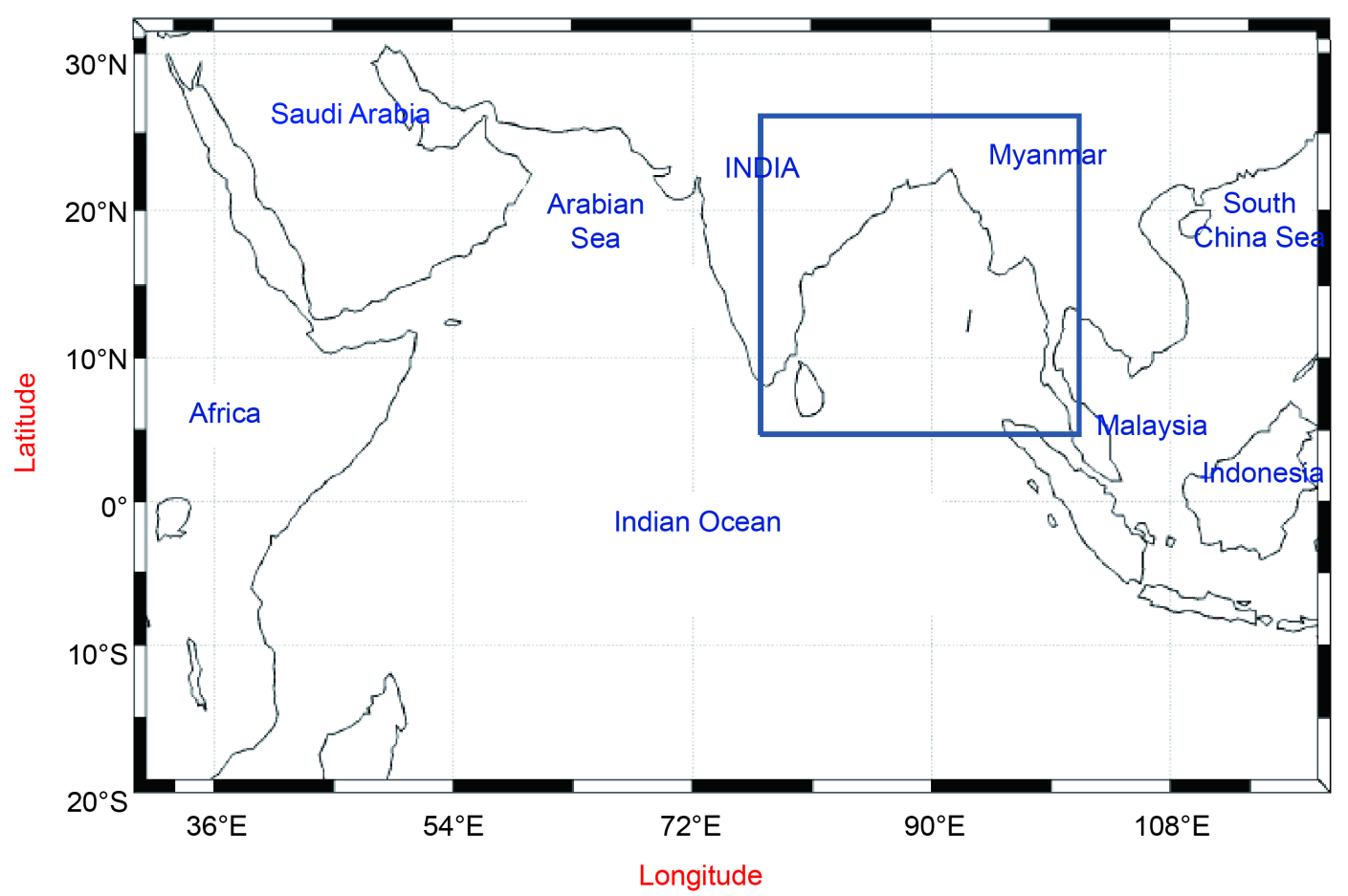

(a)

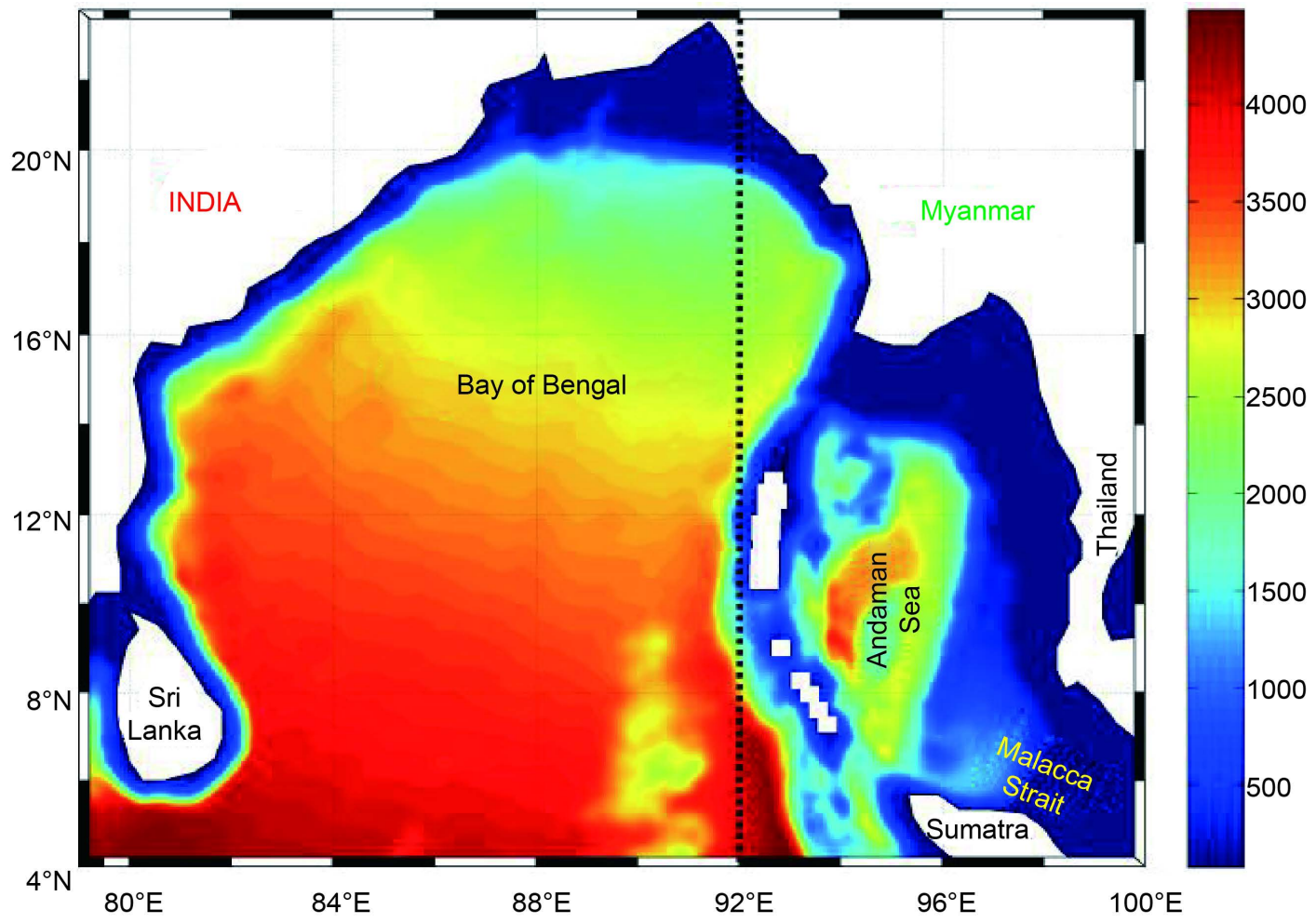

(b)

Figure 1. (a) Location of the Indian Ocean, Arabian Sea, Bay of Bengal and South China Sea. The Bay of Bengal (smaller domain) is the region of the eastern North Indian Ocean that is surrounded by India, Bangladesh, Myanmar, Thailand and northern Sumatra Island; (b) Magnification showing the position of the Bay of Bengal. The color map indicates the bathymetry in meters. 


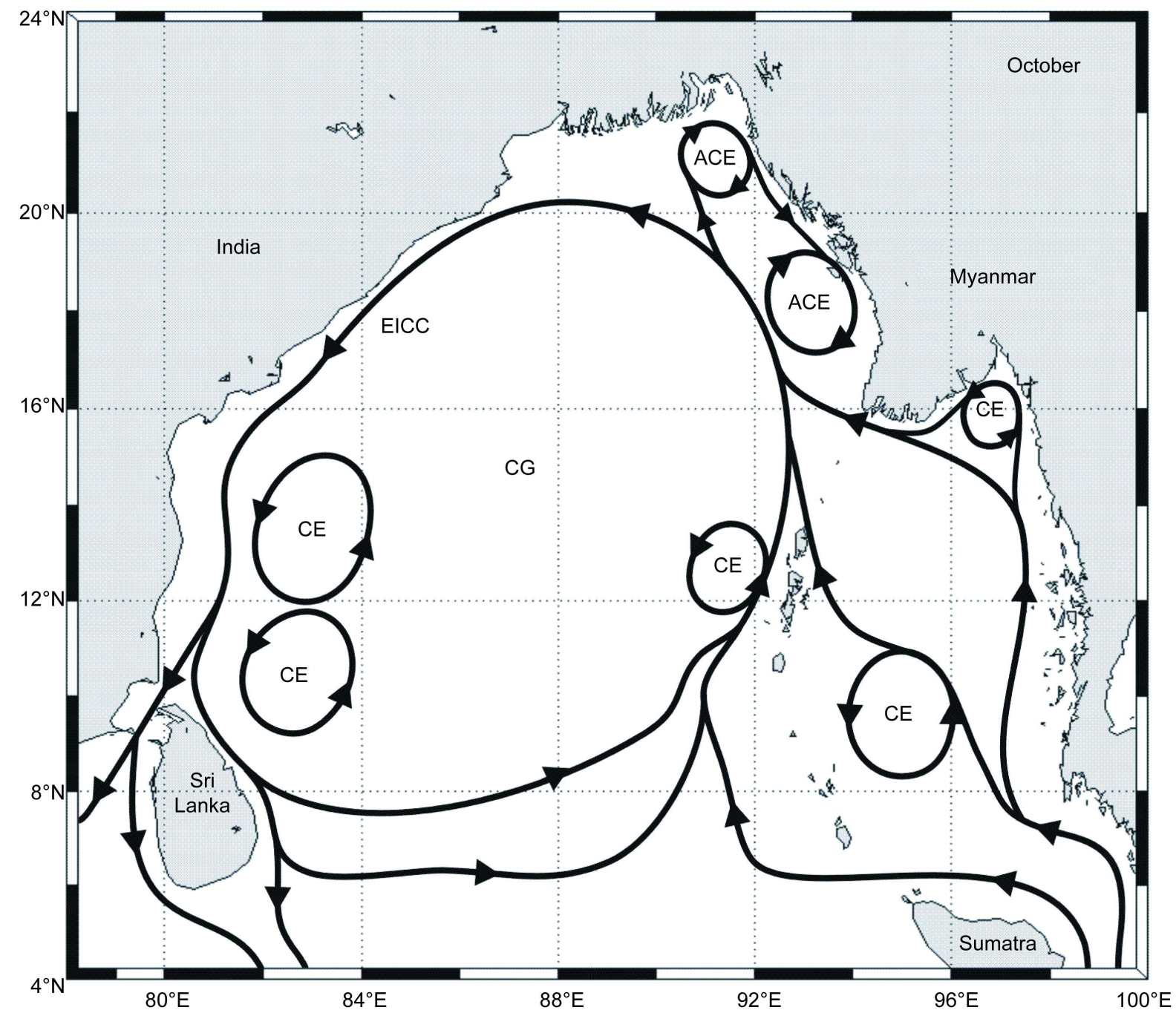

Figure 2. Schematic diagram of the prevalent features during October that were derived from different observational studies. The EICC and basin-scale cyclonic gyre are the broad-scale features of the basin during October. There are also a few mesoscale eddies during this time.

Table 1. List of relevant studies used to identify the features.

\begin{tabular}{cc}
\hline Features & Relevant studies \\
\hline EICC & {$[3][6][8][22]-[26]$} \\
Basin scale CG & {$[3][7][8][10][26]$} \\
Anti-cyclonic gyre at head Bay of Bengal & {$[3][10][27]-[29]$} \\
\hline
\end{tabular}

and then moves northward to join with the EICC at $20^{\circ} \mathrm{N}$ to complete a basin-scale cyclonic gyre in the Bay of Bengal [10]. There are anticyclonic eddies near the Myanmar coast that cause both the eastern boundary and the western boundary currents of the North Bay to move southward. A portion of the Malacca Strait flow moves northward along the eastern boundary and then meets the basin-wide CG around $15^{\circ} \mathrm{N}$.

At $100 \mathrm{~m}$, the surface basin-scale cyclonic gyre shows its signature. In addition to the CG at the subsurface, there are also cyclonic eddies $\left(86.5^{\circ} \mathrm{E}, 19^{\circ} \mathrm{N} ; 82.5^{\circ} \mathrm{E}, 14^{\circ} \mathrm{N} ; 79.5^{\circ} \mathrm{E}, 5^{\circ} \mathrm{N} ; 83^{\circ} \mathrm{E}, 10^{\circ} \mathrm{N}\right)$ on the western side of the basin, and anticyclonic eddies $\left(97^{\circ} \mathrm{E}, 7^{\circ} \mathrm{N} ; 95^{\circ} \mathrm{E}, 12^{\circ} \mathrm{N} ; 91^{\circ} \mathrm{E}, 17^{\circ} \mathrm{N}\right)$ on the eastern side of the basin are the prevalent features during October. Incoming flow from the Indian Ocean to the BOB between $80^{\circ} \mathrm{E}$ to $90^{\circ} \mathrm{E}$ is 
another feature during October [9]. Two anti-cyclonic eddies $\left(95^{\circ} \mathrm{E}, 12^{\circ} \mathrm{N} ; 97^{\circ} \mathrm{E}, 7^{\circ} \mathrm{N}\right)$ in the Andaman Sea are also features of this level. In a deeper zone, the western Bay is covered with a cyclonic gyre with currents following the boundary, and the Andaman Sea is covered with an anticyclonic gyre.

\section{Data, Model and Methodology}

The ROMS used in our study [3] is a free-surface, hydrostatic, primitive equation ocean model [2] with a stretched terrain-following S-coordinate system. The primitive equations are written using boundary-fitted, orthogonal, curvilinear coordinates on a staggered Arakawa $\mathrm{C}$ grid [1]. This regional model was configured for the BOB region $\left(4^{\circ} \mathrm{N}-24^{\circ} \mathrm{N}, 79^{\circ} \mathrm{E}-100^{\circ} \mathrm{E}\right)$ with $256 \times 249$ grid points in the horizontal surface approximately 10 $\mathrm{km}$ resolution. The northern, eastern and major parts of the western boundaries were closed, while the southern boundary was open. On the open boundary, the temperature and salinity values were relaxed to the Levitus monthly climatology. The vertical turbulent mixing was based on the K-profile parameterization (KPP) vertical mixing scheme. The model consists of $32 \mathrm{~S}$-coordinate layers in the vertical, and the bottom topography was based on the Earth Topography Two-Minute digital terrain model (ETOPO2) data (Figure 1(b)).

The following data were used to create the initial fields: the Levitus temperature and salinity climatology fields on the $0.25^{\circ} \times 0.25^{\circ}$ [4] [5] grid (Figure 3(a), Figure 3(b)); the ocean observational ARGO data sets for the month of October 2008 (overlaid in Figure 3(a)); and the SST measured by the TMI on a $0.25^{\circ} \times 0.25^{\circ}$ grid that passed over the BOB region during October 4-6, 2008. The TMI data was obtained from

ftp://ftp.ssmi.com/tmi/bmaps_v04/. Because the TMI composite values are high near the coast and are not realistic [11], the temperature data near the coast were removed (Figure 4(a)). These temperature data were then subsampled for every grid point to construct the synthetic temperature profile $\left(T_{\text {syn }}\right)$ using Equation (1) as follows:

$$
\begin{gathered}
T_{\text {syn }}(x, y, z)=\left[T_{T M I}(x, y)-T_{b}(x, y)\right] * \varphi(x, y, z)+T_{b}(x, y) \text { for } 0 \leq z \leq H \\
\varphi(x, y, z)=\frac{\left[T(x, y, z)-T_{b}(x, y)\right]}{\left[T_{s}(x, y)-T_{b}(x, y)\right]} \text { for } 0 \leq z \leq H
\end{gathered}
$$

where $\varphi(x, y, z)$ is the non-dimensional structiure function, $T_{s}(x, y)$ is the surface temperature from Levitus Climaotology, $T_{b}(x, y)$ is the Levitus temperature at depth $H$ and $T_{T M I}(x, y)$ is the TMI SST.

To prepare the initial field on the model grid points, an objective analysis (OA) procedure [12]-[14] was performed with the synthetic profiles of temperature and Levitus salinity profiles using the Levitus October climatology as the background. OA has the advantage over the direct interpolation from the Levitus grid of modeling the grid by keeping the dynamical feature information intact [13] and melding the satellite and in-situ data in an optimal statistical way. The multiscale OA parameters used are given in Table 2.

The OA fields for the temperature of TMI with the climatology background (TMI-Climo-1/4) and ARGO plus TMI with the climatology background (ARGO-TMI-Climo-1/4) showed the same structure at the surface because ARGO has no data points at the surface. The impact of TMI on the initial surface fields for October 4-6, 2008 can be clearly seen in Figure 4(b). The Levitus temperature climatology of October showed a warmer region in the upper part of the Bay of Bengal and a colder region from the southern side of the basin to the lower part of the Andaman Sea (Figure 3(a)), but the surface structures were different for October 2008 (Figure 4(a), Figure 4(b)). The western side of the basin was slightly warmer, and there was a large warmer region in the central part of the basin around $10^{\circ} \mathrm{N}$ (Figure 4(b)). A number of mesoscale features are apparent in the objectively analyzed temperature field (Figure 4(b)) throughout the basin. The temperature structures at a 100-m depth in the TMI with the climatology background (TMI-Climo-1/4) and ARGO plus TMI with the climatology background (ARGO-TMI-Climo-1/4) are shown in Figure 5(a) and Figure 5(b), respectively. Similarly, the OA salinity fields are shown in Figure 5(c) and Figure 5(d). These figures show that the eastern side of the basin was warmer with lower salinity compared to the western side of the basin, which was highly saline and cold. The small-scale features with warm-core and cold-core regions were observed both for the TMI and the TMI with the ARGO-based objective analysis. Many small-scale features $\left(84.5^{\circ} \mathrm{E}, 9^{\circ} \mathrm{N} ; 89^{\circ} \mathrm{E}, 13^{\circ} \mathrm{N} ; 93^{\circ} \mathrm{E}, 17^{\circ} \mathrm{N}, 91^{\circ} \mathrm{E}\right.$, $8.5^{\circ} \mathrm{N} ; 93.5^{\circ} \mathrm{E}, 5^{\circ} \mathrm{N}$ ) were observed with the ARGO-based OA (Figure 5(b) and Figure 5(d)) compared to without the ARGO-based OA (Figure 5(a) and Figure 5(c)), indicating the impact of ARGO on the climatology data used to generate the synoptic initial fields. 

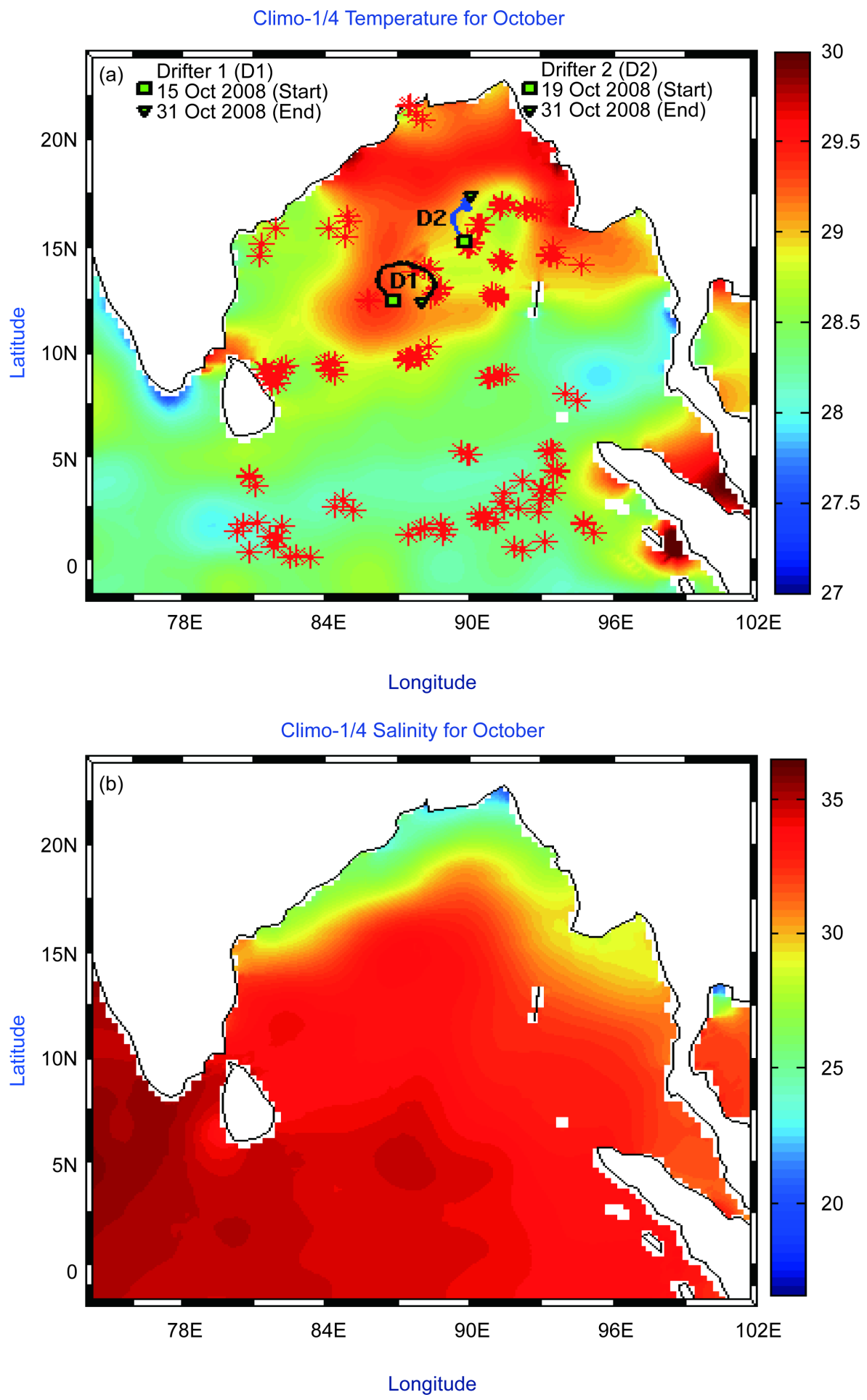

Figure 3. (a) October surface temperature climatology of Levitus. The red stars indicate the locations of 153 ARGO profiles for the month of October 2008. Drifter D1 started on October 15, 2008 and ended on October 31, 2008, and drifter D2 started on October 19, 2008 and ended on October 31, 2008. These two drifters were used for model validation. The larger domain was considered for OA; (b) October surface salinity climatology of Levitus, which showed low salinity in the northern Bay of Bengal that extended along the coasts to $15^{\circ} \mathrm{N}$. Note that the larger domain was chosen for the OA computation. 
Table 2. Multiscale OA parameters.

\begin{tabular}{ccc}
\hline OA parameters & Climatology large-scale $(\mathrm{km})$ & Mesoscale $(10 \mathrm{~km}$ resolution) $(\mathrm{km})$ \\
\hline Zero-crossing $(\mathrm{x} / \mathrm{y})$ & $300 / 300$ & $150 / 150$ \\
Radius of influence $(\mathrm{x} / \mathrm{y})$ & $150 / 150$ & $75 / 75$ \\
\hline
\end{tabular}

SST Composite for 4,5 and 6 October, 2008
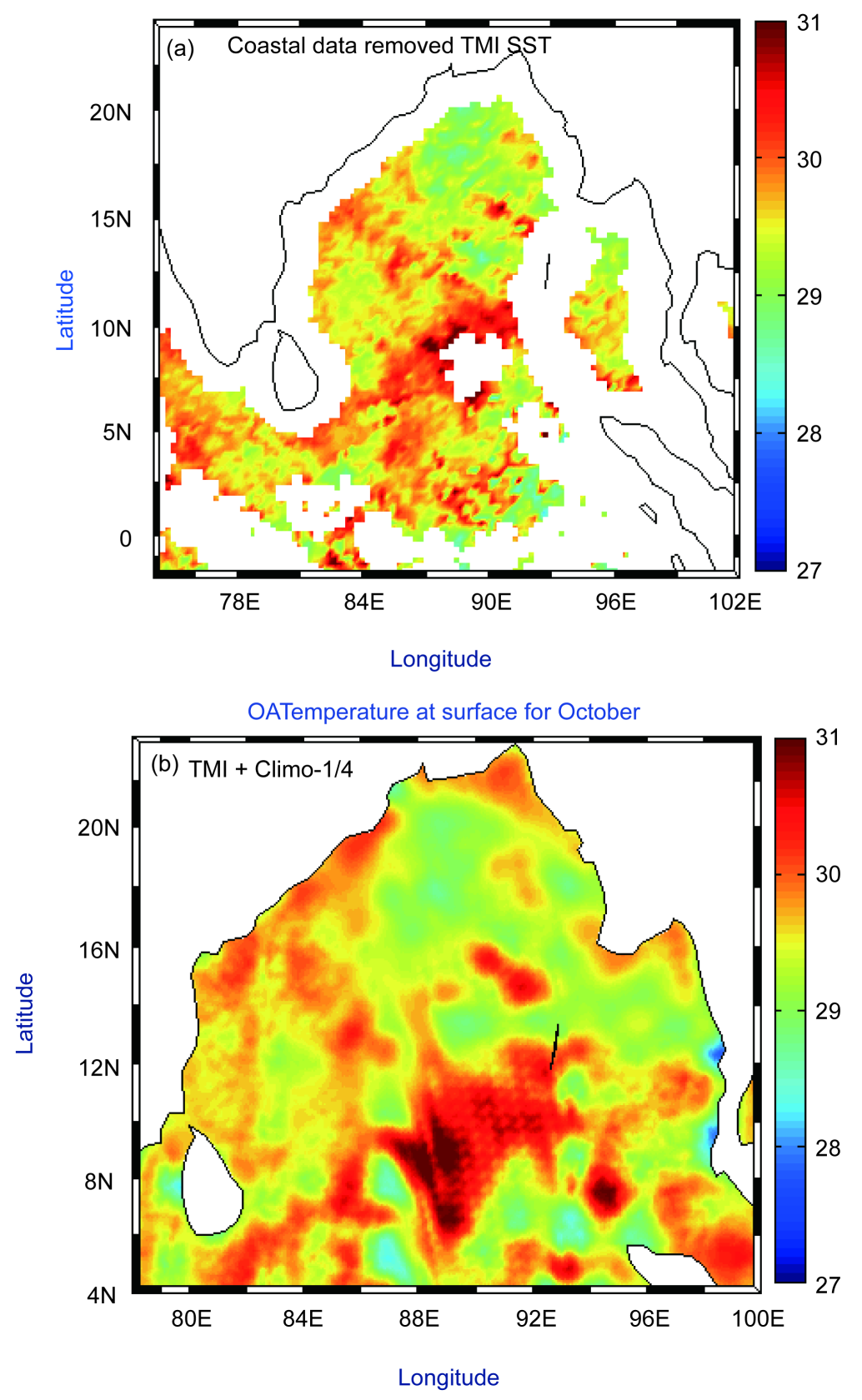

Figure 4. (a) Composite picture of the sea surface temperature derived from the TMI that passed over the Bay of Bengal on October 4-6, 2008. The coastal temperature was removed because the TMI satellite picture showed hotter regions along the coast; (b) The model initial field of temperature for the month of October 2008 at the surface derived from OA fields for Exp-2 and Exp-3. Note that the larger domain in (a) was chosen for OA computation. 

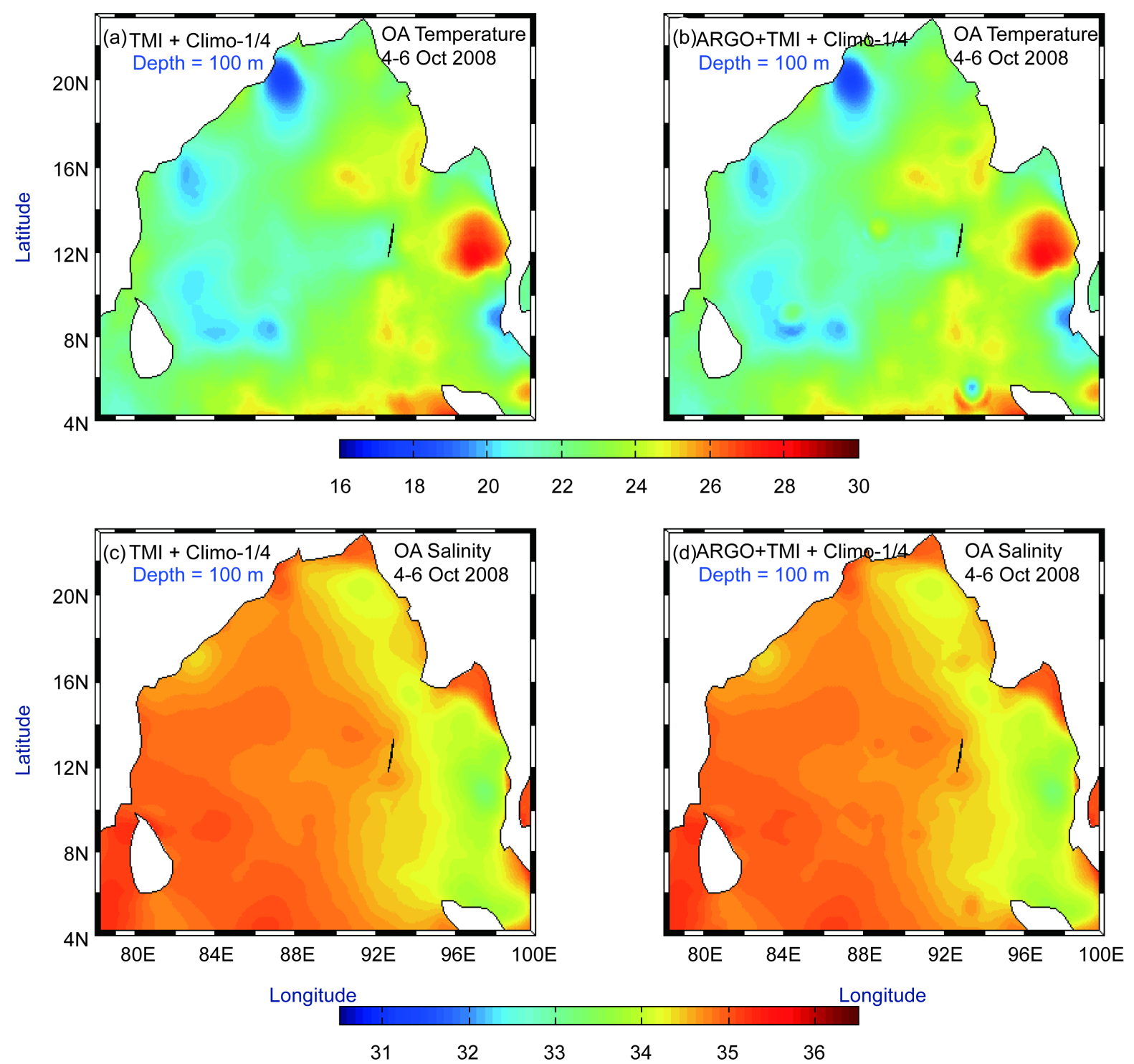

Figure 5. The model initial field of temperature for the month of October 2008 at the depth of $100 \mathrm{~m}$ derived from OA fields is shown for (a) Exp-2 and (b) Exp-3. The model initial field of salinity for the month of October 2008 at the depth of $100 \mathrm{~m}$ derived from OA fields is shown for (c) Exp-2 and (d) Exp-3. The impact of ARGO was seen in Exp-3 at this depth.

\section{Experimental Setup}

The following three short-term (30 day) model experiments were conducted, using October 4-6, 2008 ARGO and satellite data-based OA as initial conditions to access the impact of TMI and ARGO data. These experiments were performed as follows: Exp-1, simulation with the Climo-1/4 data as initial fields; Exp-2, simulation with the TMI-Climo-1/4 data as initial fields; and Exp-3, simulation with the ARGO-TMI-Climo-1/4 data as initial fields. The model was forced with COADS (Comprehensive Ocean Atmosphere Data Set) October climatology-based surface forcing.

It is well known that short-term climatology-based simulations require the three-dimensional specifications of the $T, S, u$ and $v$ initial fields, but the standard practice for a basin-scale numerical modeling experiment is to specify $T$ and $S$ only with zero velocity [15] [16]. In this procedure, the model requires a spin-up time that may be from one to ten years [17] to develop the momentum fields. As discussed in our Part I paper, our goal was to develop a system for short-term synoptic forecasting for use in situations in which we want to avoid long simulations. For this reason, we specified the best possible velocity field in addition to the mass ( $T$ and $S$ ) field for 
synoptic short-term simulations at initialization. The initial geostrophic velocity was computed from the temperature and salinity by the OA methodology [13] described above. Similar initialization methodology and their internal adjustment procedures were described by [15] [17]-[19].

\section{Evaluation against Climatology Simulation}

The time evolutions of kinetic energy for the different simulation experiments are shown in Figure 6. The kinetic energy slowly increased with the time of integration in all simulations. The kinetic energy for the TMI simulation (Exp-2) was larger than that for the climatology simulation (Exp-1) and less than that for the TMI plus ARGO simulation (Exp-3). It can be inferred from this figure that both TMI and ARGO introduced many mesoscale features to the climatology data, and as a result, the kinetic energy increased.

\subsection{Circulation Features}

\subsubsection{Surface}

The surface circulations for Exp-1, Exp-2 and Exp-3 are shown in Figure 7, Figure 8 and Figure 9, respectively. The surface circulation features for Exp-2 and Exp-3 (Figure 8 and Figure 9) were much more prominent than those in Exp-1 (Figure 7), with few additional features. The development of a well-defined coast following the East India Coastal Current (EICC), which moves toward the equator [6], was observed in all the experiments from day 6 to day 15 of the model integrations. The bifurcation of the EICC at the northern tip of Sri Lanka and the flow of the branches were well approximated by all of the model simulations. The basin-scale cyclonic gyre in the Bay of Bengal could be seen in the model simulation experiments from day six (Figure 7(a), Figure 8(a), Figure 9(a)). This gyre was more organized, and its boundary current strength (Figure 7(b), Figure 8(b), Figure 9(b)) was comparable with observations [10] for day 15 of the model simulation experiments (Figure 7(c), Figure 8(c), Figure 9(c)). The flow to the Andaman Sea region from the South China Sea via the Malacca Strait [6], which was observed in Exp-1 (Figure 7(c)), was also seen in the Exp-2 (Figure 8(c)) and Exp-3 (Figure 9(c)) model simulations. The last two simulation experiments demonstrated that the penetration of this flow to the Bay of Bengal was eastward and the flow to the Indian Ocean was southward from the northern tip of Sumatra Island (Figure 8(d), Figure 9(d)). The surface flow through the Palk Strait to the Arabian Sea from the Bay of Bengal was seen for all of the model simulations. The Anticyclonic Gyre (AG) in the northeastern side of the head bay $\left(93^{\circ} \mathrm{E}, 18^{\circ} \mathrm{N}\right)$, which triggers the southward movement of both eastern boundary and western boundary currents, was prominent from day 6 to day 15 of the model integrations for Exp-2 (Figures 8(a)-(d)) and Exp-3 (Figures 9(a)-(d)). The eastern boundary current above $16^{\circ} \mathrm{N}$ was strong on day 15 for the Exp-2 (Figures 8(c), Figure 8(d)) and Exp-3 (Figure 9(c), Figure 9(d)) model simulation experiments. The mesoscale eddies were prominent in the model simulations from day six of the model integration (Figure 7(a), Figure 8(a), Figure 9(a)). The mesoscale anticyclonic eddies around the centers at $91^{\circ} \mathrm{E}, 21^{\circ} \mathrm{N}$ and $93^{\circ} \mathrm{E}, 18^{\circ} \mathrm{N}$ and cyclonic eddies

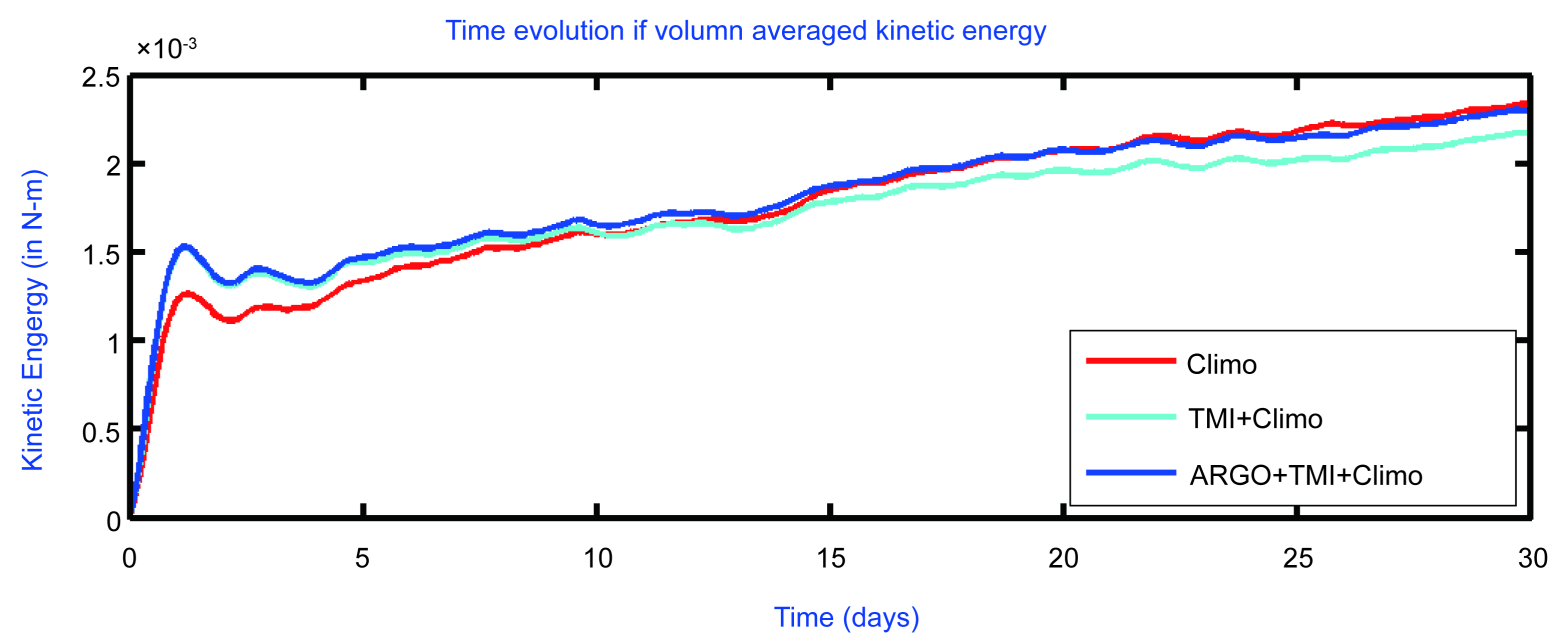

Figure 6. Time evolution of the volume-averaged kinetic energy in the model experiments (Exp-1, Exp-2 and Exp-3). 

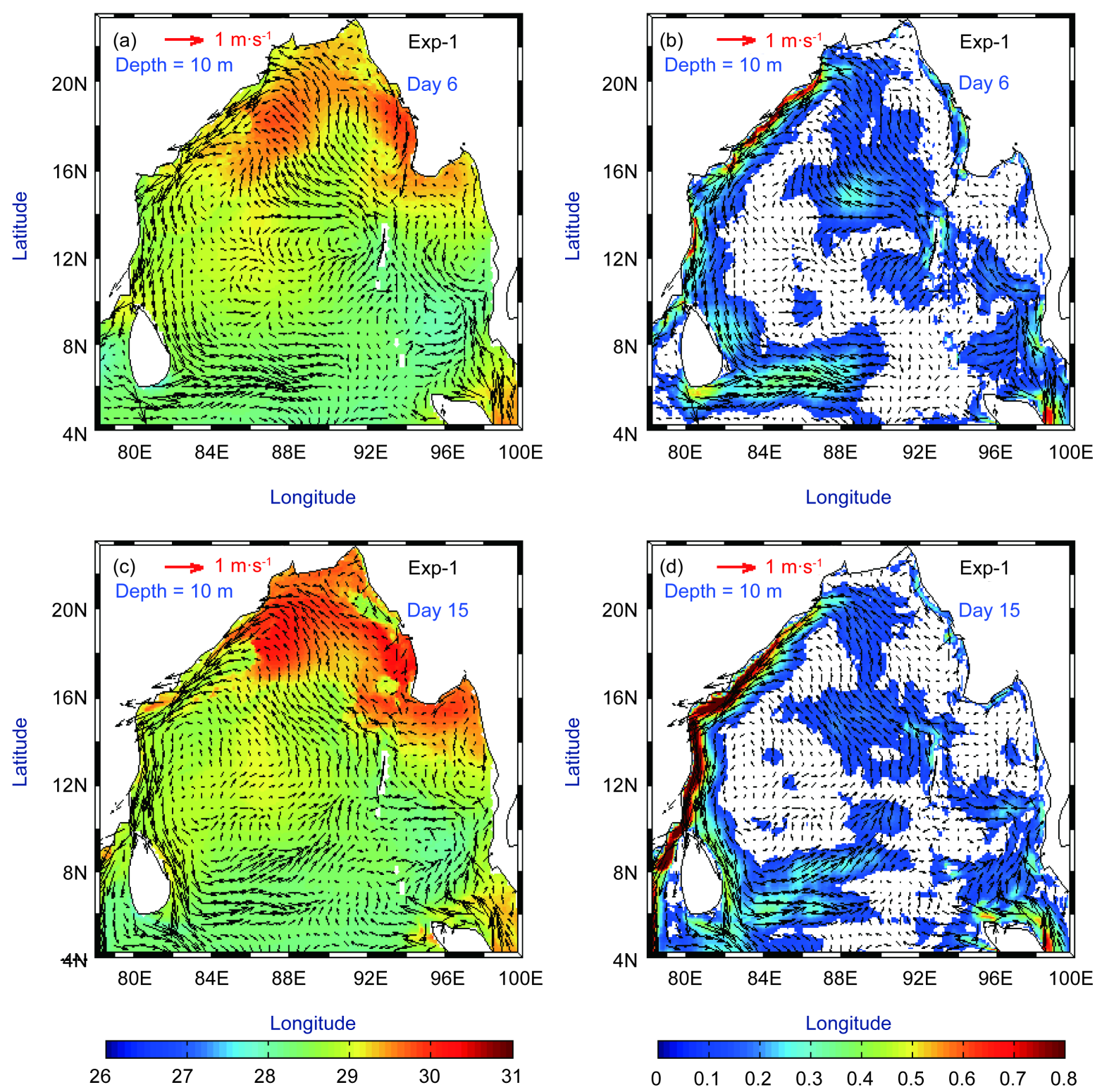

Figure 7. (a) Model-simulated currents (vectors) with temperature (colored for Exp-1 at the depth of $10 \mathrm{~m}$ for day six; (b) Model-simulated currents (vectors) with magnitude (color shaded) for Exp-1 at the depth of $10 \mathrm{~m}$ for day six; (c) Model-simulated currents (vectors) with temperature (color shaded) for Exp-1 at the depth of $10 \mathrm{~m}$ for day 15; (d) Model-simulated currents (vectors) with magnitude (colored) for Exp-1 at the depth of $10 \mathrm{~m}$ for day 15.

around the centers at $97^{\circ} \mathrm{E}, 16^{\circ} \mathrm{N} ; 95^{\circ} \mathrm{E}, 10^{\circ} \mathrm{N} ; 83^{\circ} \mathrm{E}, 11^{\circ} \mathrm{N} ; 83^{\circ} \mathrm{E}, 13^{\circ} \mathrm{N}$; and $91^{\circ} \mathrm{E}, 12.5^{\circ} \mathrm{N}$ were apparent in all three simulation experiments (Figure 7(c), Figure 8(c), Figure 9(c)).

The systematic growth and decay of some of eddies were also seen in the simulation experiments. An anti-cyclonic eddy with a center at $\left(97^{\circ} \mathrm{E}, 11^{\circ} \mathrm{N}\right)$ and a radius of approximately $100 \mathrm{~km}$ was seen on day six of the model simulations for Exp-2 (Figure 8(a)) and Exp-3 (Figure 9(a)) experiments but was not seen in Exp-1 (Figures 7(a)-(d)). This eddy shifts the location slightly, but the size is decreased by almost one half (center at $97^{\circ} \mathrm{E}, 11^{\circ} \mathrm{N}$ with a radius of $\sim 50 \mathrm{~km}$ ) on day 15 of the model integration (Figure 8(d), Figure 9(d)). The cyclonic eddy $\left(97^{\circ} \mathrm{E}, 9^{\circ} \mathrm{N}\right)$ and anticyclonic eddy $\left(99^{\circ} \mathrm{E}, 6^{\circ} \mathrm{N}\right)$ discussed above were not observed in the climatology experiment (Exp-1). The overall surface currents were stronger for Exp-2 and Exp-3 than for the climatology simulation $(\operatorname{Exp}-1)$. The AG overhead bay $\left(93^{\circ} \mathrm{E}, 18^{\circ} \mathrm{N}\right)$ was also stronger and more distinct for Exp-2 and Exp-3 compared to the climatology-based simulation. 

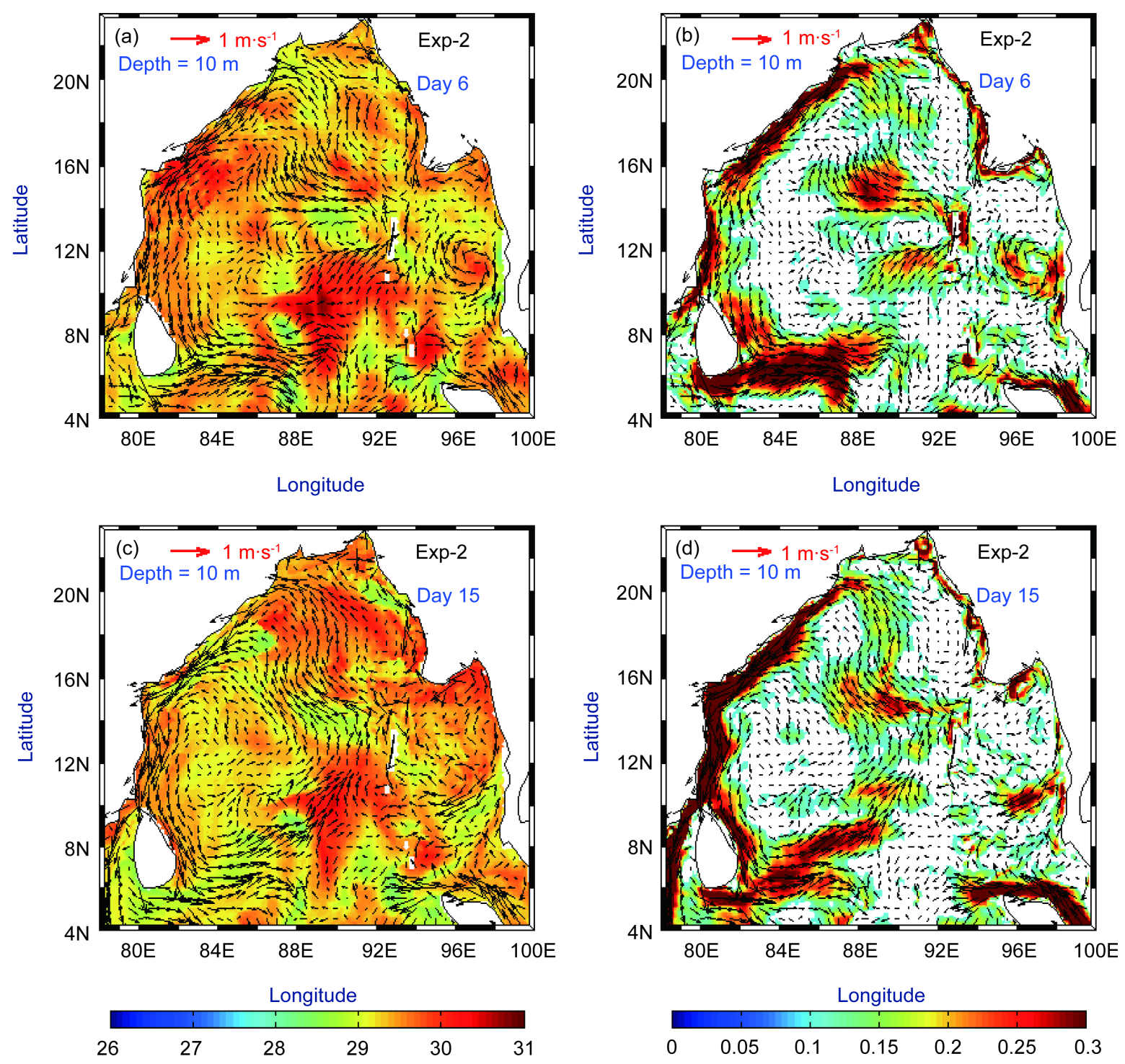

Figure 8. (a) Model-simulated currents (vectors) with temperature (colored) for Exp-2 at the depth of $10 \mathrm{~m}$ for day six; (b) Model-simulated currents (vectors) with magnitude (colored) for Exp-2 at the depth of $10 \mathrm{~m}$ for day six; (c) Model-simulated currents (vectors) with temperature (colored) for Exp-2 at the depth of $10 \mathrm{~m}$ for day 15; (d) Model-simulated currents (vectors) with magnitude (colored) for Exp-2 at the depth of $10 \mathrm{~m}$ for day 15.

\subsubsection{Subsurface}

The basin-scale cyclonic gyre with southward-flowing EICC that is observed at the surface was also seen at the subsurface depth (Figures 10(a)-(f)), but it was smaller in size. This gyre was observed in the climatology-based simulation, Exp-1 (Figure 10(a), Figure 10(b)), and also with the TMI and ARGO simulation experiments, Exp-2 and Exp-3 (Figure 10(b), Figure 10(c) and Figure 10(d), Figure 10(f)). The features were more prominent on day 15 (Figure 10(b), Figure 10(d) \& Figure 10(f)) of the model simulation experiments compared to day 6 (Figure 10(a), Figure 10 (c) \& Figure $10(\mathrm{e})$ ). The cyclonic eddies $\left(86.5^{\circ} \mathrm{E}, 19^{\circ} \mathrm{N} ; 82.5^{\circ} \mathrm{E}, 14^{\circ} \mathrm{N} ; 79.5^{\circ} \mathrm{E}\right.$, $\left.5^{\circ} \mathrm{N} ; 83^{\circ} \mathrm{E}, 10^{\circ} \mathrm{N}\right)$ on the western side of the basin and anticyclonic eddies $\left(97^{\circ} \mathrm{E}, 7^{\circ} \mathrm{N} ; 95^{\circ} \mathrm{E}, 12^{\circ} \mathrm{N} ; 91^{\circ} \mathrm{E}, 17^{\circ} \mathrm{N}\right)$ on the eastern side of the basin were observed for all three simulation experiments (Figure 10(b), Figure 10(d) \& Figure 10(f)). All of these circulation features were distinct and strong for Exp-2 (Figure 10(d)) and Exp-3 (Figure 10(f)) compared to Exp-1 (Figure 10(b)). The prominent anti-cyclonic eddies at $95^{\circ} \mathrm{E}, 12^{\circ} \mathrm{N}$ and $97^{\circ} \mathrm{E}$, $7^{\circ} \mathrm{N}$ in the Andaman Sea that were observed in Exp-1 (Figure 10(b)) were also observed in the Exp-2 (Figure 10(d)) and Exp-3 (Figure 10(f)) simulation experiments. No extra prominent features were seen on the 

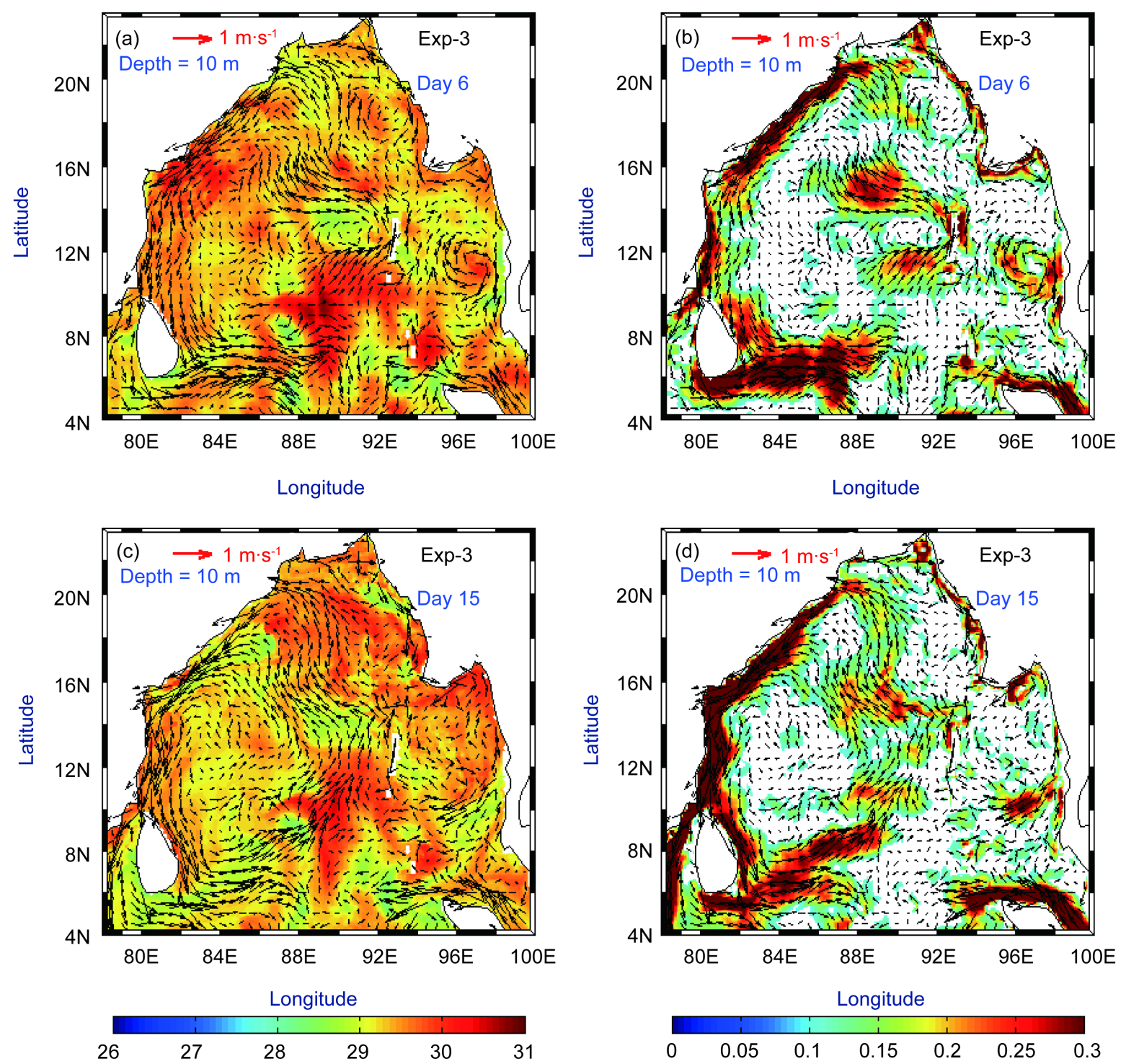

Figure 9. (a) Model-simulated currents (vectors) with temperature (colored) for Exp-3 at the depth of $10 \mathrm{~m}$ for day six; (b) Model-simulated currents (vectors) with magnitude (colored) for Exp-3 at the depth of $10 \mathrm{~m}$ for day six; (c) Model-simulated currents (vectors) with temperature (colored) for Exp-3 at the depth of $10 \mathrm{~m}$ for day 15; (d) Model-simulated currents (vectors) with magnitude (colored) for Exp-3 at the depth of $10 \mathrm{~m}$ for day 15.

western side of the basin, but several extra features were observed on the eastern side of the basin. These were the small cyclonic gyres with centers at $93^{\circ} \mathrm{E}, 5^{\circ} \mathrm{N}$ and $97^{\circ} \mathrm{E}, 11^{\circ} \mathrm{N}$ in Exp-2 (Figure 10(d)) and Exp-3 (Figure $10(f))$.

These gyres result from the impact of TMI and ARGO at the subsurface because they were not observed in the climatology-based simulation. The western side of the basin is colder than the eastern side at the subsurface, which was seen from these simulation experiments (Figure 10(b), Figure 10(d) \& Figure 10(f)). Other basic structures at this depth remained the same for all the simulation experiments, but the cyclonic gyres at $86.5^{\circ} \mathrm{E}$, $19^{\circ} \mathrm{N}$, at $82.5^{\circ} \mathrm{E}, 15^{\circ} \mathrm{N}$ and at $83^{\circ} \mathrm{E}, 10^{\circ} \mathrm{N}$ were more prominent in Exp-2 (Figure $10(\mathrm{~d})$ ) and Exp-3 (Figure 10(f)) than in Exp-1 (Figure 10(b)). The strong southward EICC with this CG makes this region a zone of upwelling, and as a result, this region is cold.

\subsubsection{Deep Ocean}

The circulation at the $1500 \mathrm{~m}$ depth showed a basin-wide cyclonic gyre for all of the simulation experiments 

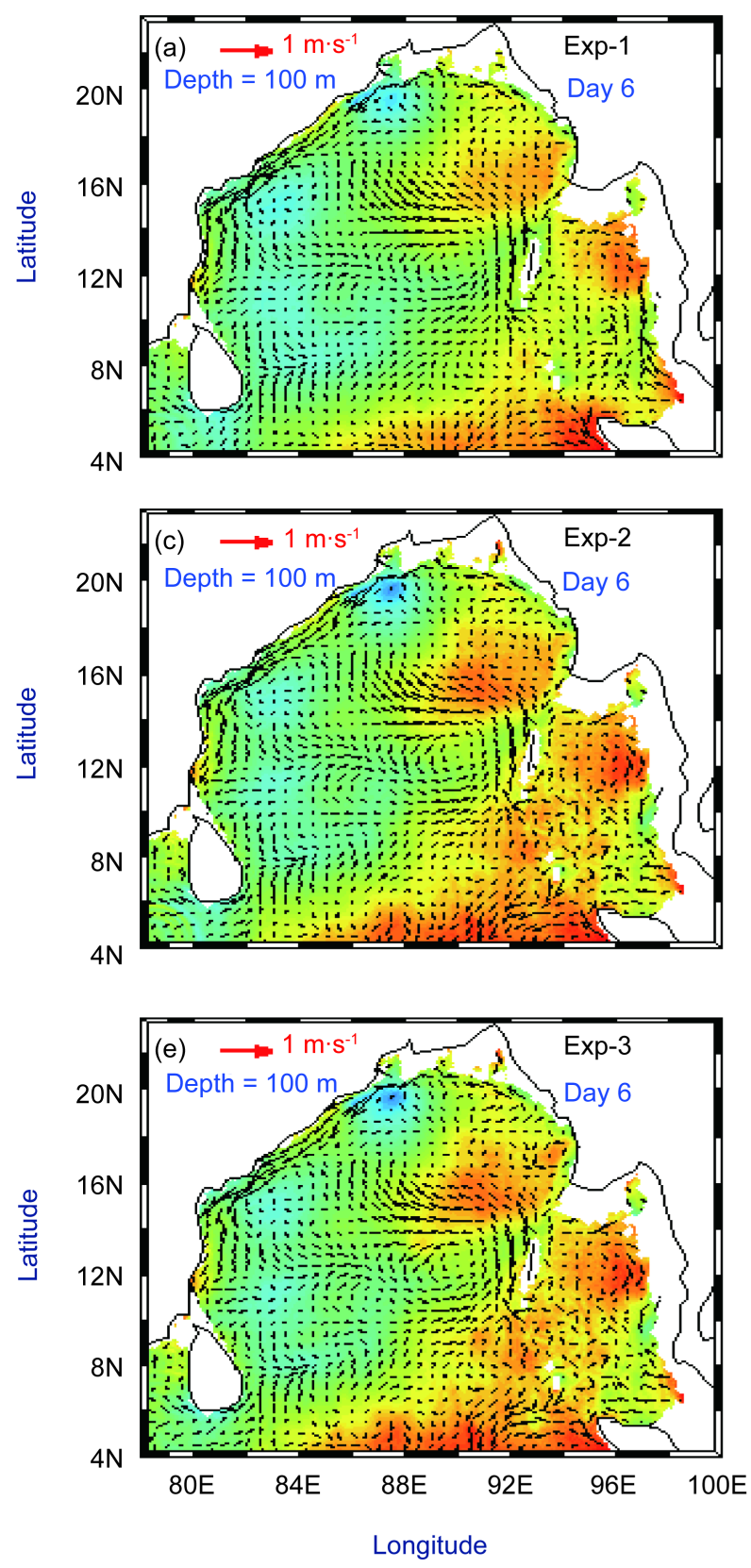
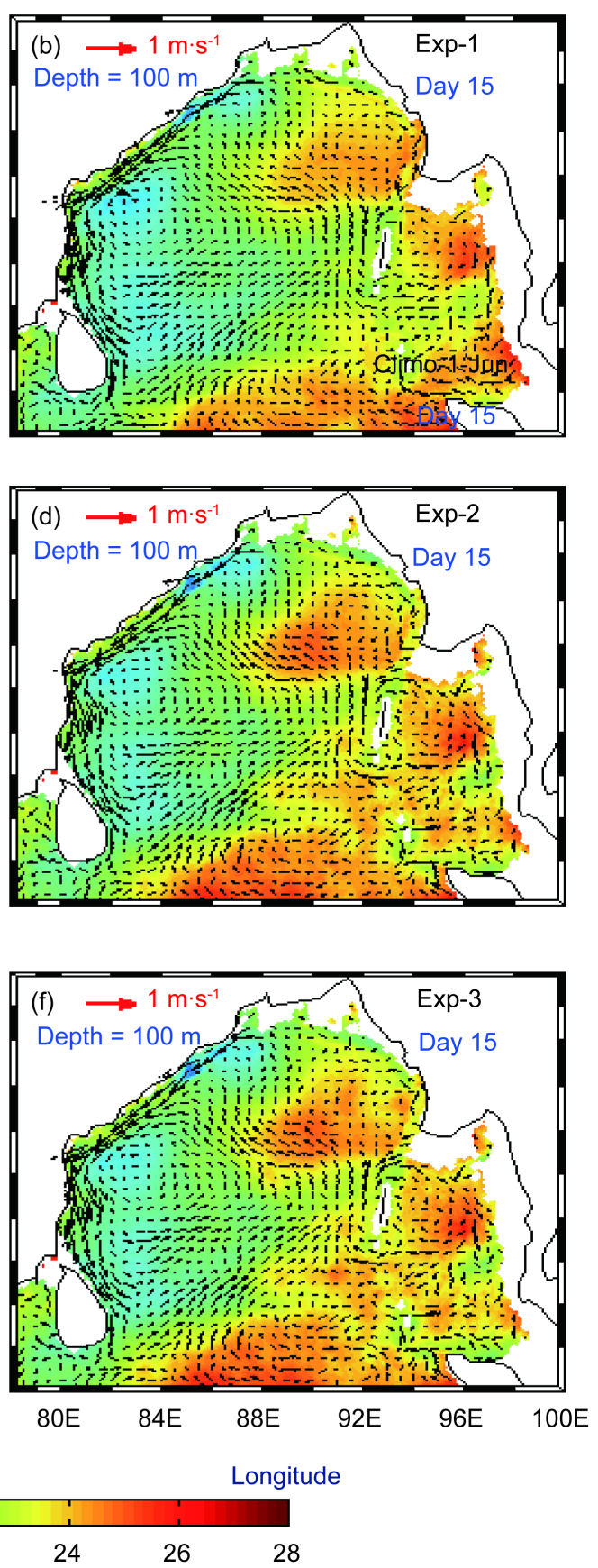

Figure 10. Model-simulated currents (vectors) with temperature (colored) at the depth of $100 \mathrm{~m}$ for (a) day 6 for Exp-1, (b) day 15 for Exp-1, (c) day 6 for Exp-2, (d) day 15 for Exp-2, (e) day 6 for Exp-3 and (f) day 15 for Exp-3.

(Figure 11(a), Figure 11(b)). The EICC was also observed at this depth on day 15 (Figure 11(b)) of the model simulation experiments, although it was not well organized on day 6 (Figure 11(a)). The northward shift of CG was observed on day 15 (Figure 11(b)) of the model simulation experiments. The flow from the Arabian Sea and Indian Ocean south of Sri Lanka was the most prominent part of the circulation of this basin at this depth. The smaller eastern basin on the Andaman Sea is isolated from the western basin at this depth and below. Its only interaction to the outer Indian Ocean regions is through a passage west of Sumatra. This solitary pathway interaction might be the reason for the existence of a warmer and saltier water mass in the deep Andaman Seas which was identified in the climatogical t-s profiles presented in Figure 2 of Part I. 


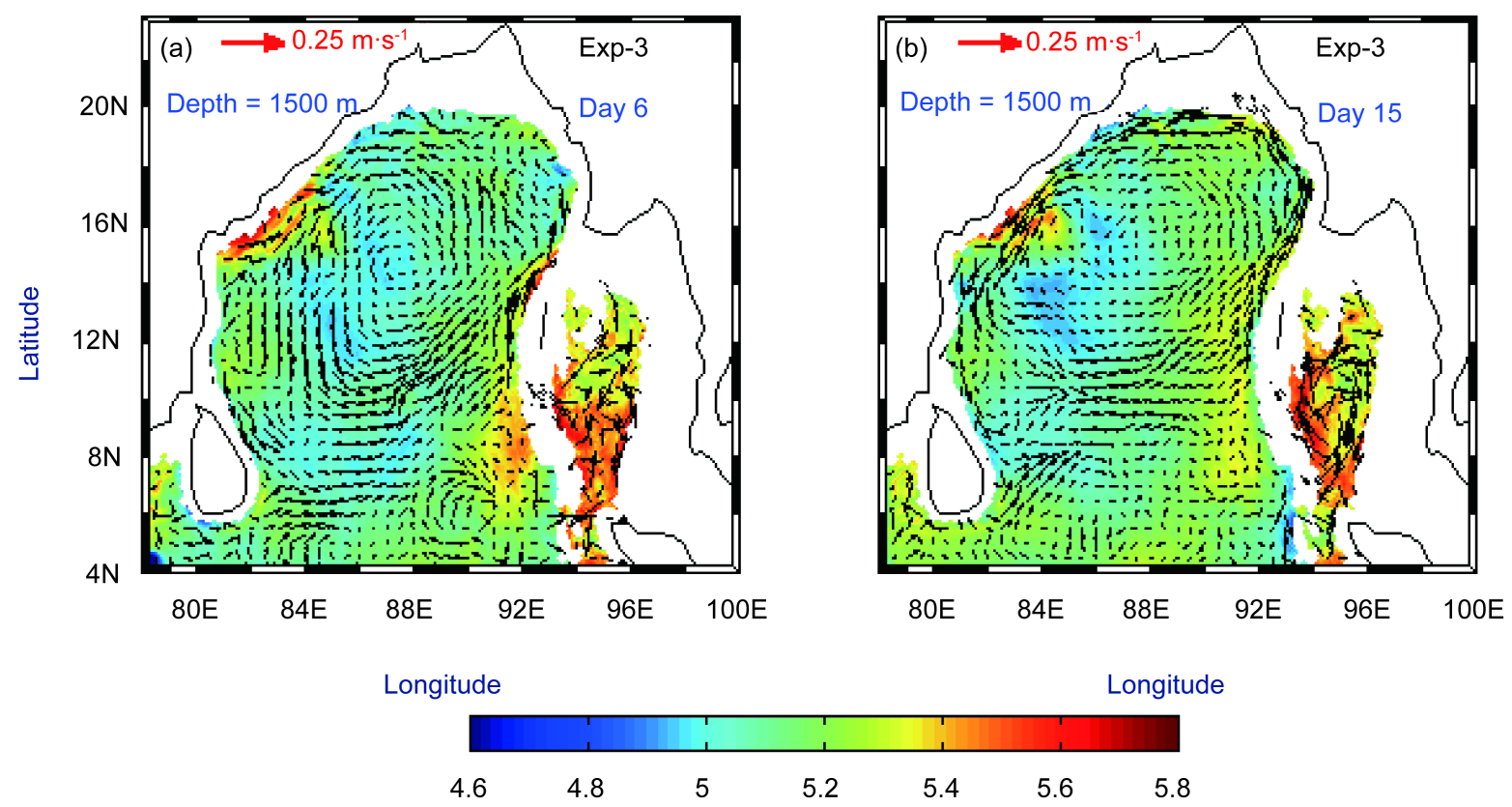

Figure 11. Model-simulated currents (vectors) with temperature (colored) at the depth of $1500 \mathrm{~m}$ for (a) day 6 for Exp-3 and (b) day 15 for Exp-3.

\subsection{Mass Transport}

The vertically integrated mass transports for the model experiments are shown in Figures 12(a)-(d). It is evident from these figures that the BOB region was dominated by a basin-wide large cyclonic gyre with its center located at $84^{\circ} \mathrm{E}, 14^{\circ} \mathrm{N}$. The CG was observed on day 6 (Figure 12(a)), but the strong EICC was observed on day 15 of the model simulation (Figures 12(b)-(d)) when the center of the maximum circulation of this CG shifted toward the western boundary of the basin. A small but strong AE in the Andaman Sea was observed in the model simulation results (Figures 12(b)-(d)). The overall circulation in the vertical integrated volume transport for the October simulation showed two opposite gyres in the basin across a line drawn from the southwest region of Sri Lanka to the south of the Myanmar region (Figures 12(b)-(d)). The formation of different mesoscale eddies at different locations was also observed. The different fields of transport on day 15 of the model simulations showed that Exp-2 enhanced the transport near the western boundary more than Exp-1 (Figure 12(e)), and Exp-3 enhanced the overall transport over the basin more than Exp-2 (Figure 12(f)).

The quantitative estimate of the volume transported in the upper $1000 \mathrm{~m}$ was computed across different sections and is shown in Table 3. The northward volumes transported at $12^{\circ} \mathrm{N}$ between $88^{\circ} \mathrm{E}$ to $92^{\circ} \mathrm{E}$ for $\operatorname{Exp}-1$, Exp-2 and Exp-3 were 5.34 Sv, 5.47 Sv and 6.26 Sv, respectively. [10] showed that the northward vertically integrated volume transported in the upper $1000 \mathrm{~m}$ along the same section is $6 \mathrm{~Sv}$, which is close to the volume estimated in $\operatorname{Exp}-3$. At $6^{\circ} \mathrm{N}$ between $80^{\circ} \mathrm{E}$ to $99^{\circ} \mathrm{E}$, the volumes transported southward were $14.58 \mathrm{~Sv}, 14.65 \mathrm{~Sv}$ and 14.81 Sv for Exp-1, Exp-2 and Exp-3, respectively. [20] showed that the volume transport for the above section is $10 \mathrm{~Sv}$, while it was reported as $16 \mathrm{~Sv}$ by [21]. The vertically integrated volume transport along the Palk Strait was southward, and it was small (0.67 Sv) for Exp-1, but the value increased to 1.06 Sv for Exp-2 and 1.08 Sv for Exp-3. Similarly, the Malacca Strait inflow increased in the experiments, but the difference among experiments was decreased; it was 2.01 Sv for Exp-1, 2.03 for Exp-2 and 2.04 for Exp-3. The magnitude of the transport increased in the model simulation when ARGO and satellite observations were included in the initial conditions. The transport values along the sections were comparable to the earlier observational studies [10] [20] [21].

\subsection{Comparison with Observations}

The simulation results from the ARGO and satellite observation-based initial conditions were compared with the ARGO profiles from October 8-31, 2008 and two drifters (D1 and D2). The drifter D1 started on October 15, 

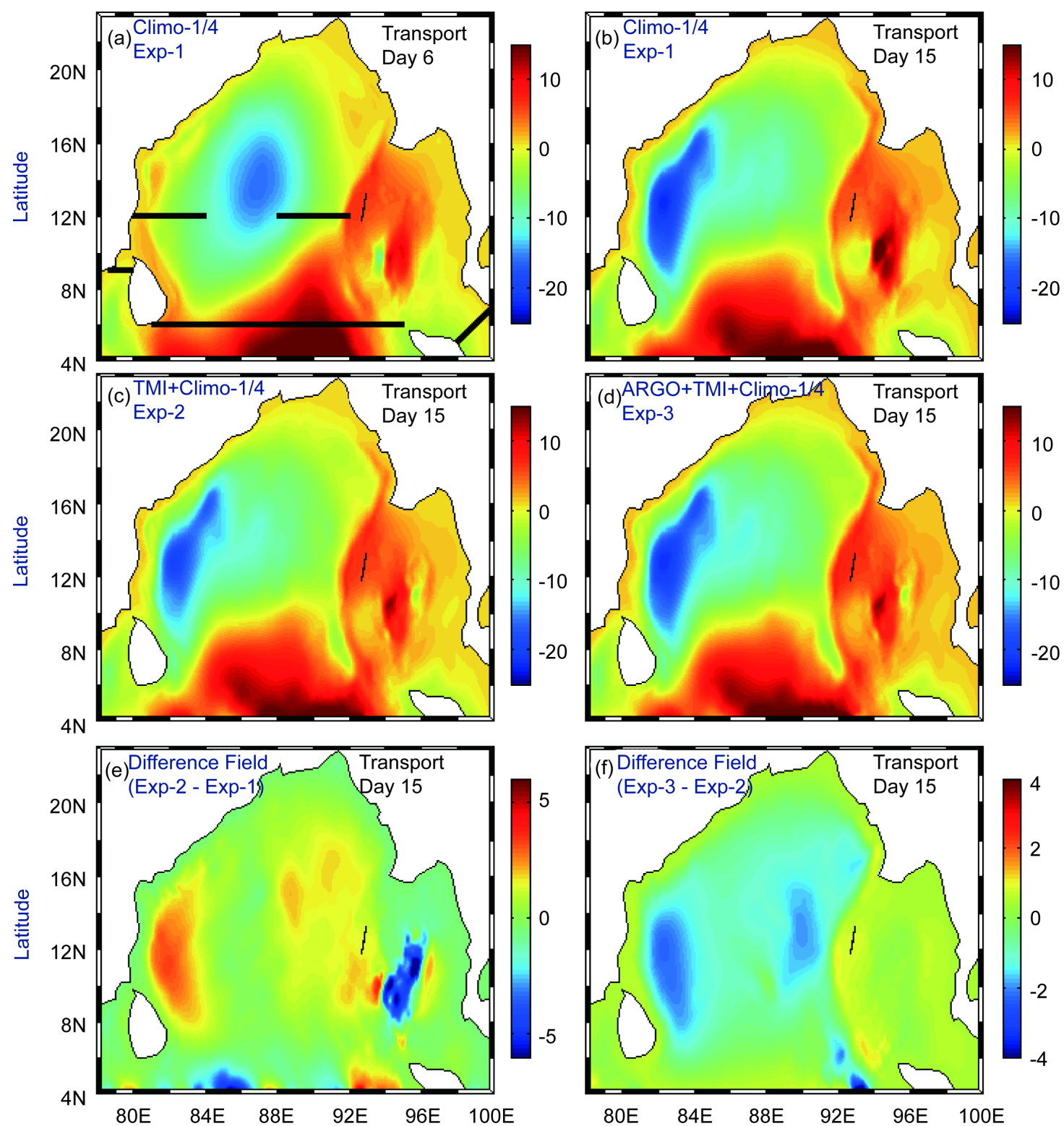

Figure 12. Model-simulated vertically integrated mass transport (Sv: $1 \mathrm{~Sv}=106 \mathrm{~m}^{3} / \mathrm{s}$ ) for (a) day 6 for Exp-1, (b) day 15 for Exp-1, (c) day 6 for Exp-2, (d) day 15 for Exp-3, (e) difference fields (Exp-2 - Exp-1) for day 15 of the simulation and (f) difference fields (Exp-3 - Exp-2) for day 15 of the simulation. Black solid lines in (a) indicate the sections along which transport values were calculated.

Table 3. Transport through the different sections.

\begin{tabular}{ccccc}
\hline & \multicolumn{2}{c}{ Transports values (Sv) of the experiments } & Observational Evidences \\
\cline { 2 - 4 } Sections & Exp-1 & Exp-2 & Exp-3 & \\
\hline $88^{\circ} \mathrm{E}-92^{\circ} \mathrm{E}, 12^{\circ} \mathrm{N}$ & 5.34 & 5.47 & 6.26 & $6 \mathrm{~Sv}[10]$ \\
Creek Channel, $9^{\circ} \mathrm{N}$ & -0.67 & -1.06 & -1.08 & - \\
Malacca Strait $98^{\circ} \mathrm{E}, 5^{\circ} \mathrm{N}$ to $100^{\circ} \mathrm{E}, 7^{\circ} \mathrm{N}$ & 2.01 & 2.03 & 2.04 & $-16 \mathrm{~Sv}[21]$ \\
$80^{\circ} \mathrm{E}-95^{\circ} \mathrm{E}, 6^{\circ} \mathrm{N}$ & -14.58 & -14.65 & -14.81 & $-10 \mathrm{~Sv}[20]$ \\
$80^{\circ} \mathrm{E}-84^{\circ} \mathrm{E}, 12^{\circ} \mathrm{N}$ & -27.72 & -27.96 & -28.07 & - \\
\hline
\end{tabular}


2008 and ended on October 31, 2008, and drifter D2 started on October 19, 2008 and ended on October 31, 2008 (Figure 1(a)).

\subsubsection{Comparison with ARGO}

The model simulations for Exp-2 were carried out with October 4-6 ARGO data-based OA as the initial conditions, and Exp-3 was carried out with October 4-6 ARGO and TMI satellite data-based OA as the initial conditions. The model validation was performed by comparing the ARGO profiles available from October 10-31 with the model-simulated profiles from day 5 to day 31 in the ARGO locations. Because of the different characteristics of the eastern and western BOB [3], the comparisons are shown separately for the two parts of the basin. Although the comparison was performed for all the available profiles, only profiles for October 10, 15 and 20, 2008 are shown with the profiles of day 5, day 10 and day 15 of the model simulation experiments (Exp-1, Exp-2 and Exp-3) in Figure 13(a) for the western BOB and Figure 13(b) for the eastern BOB. The model performed well because almost all of the profiles were comparable with the observations (Figure 13(a), Figure 13(b)). It was also observed from these profiles that Exp-2 was better than Exp-1, and Exp-3 was better than Exp-2. In the mixed layer, the temperature was slightly lower for the model simulations than for the ARGO profiles (Figure 13(a), Figure 13(b)). It was observed that in the eastern side of the basin (Figure 13(b)) for the model simulation, the thermocline deepened, whereas in the western side of the basin (Figure 13(a)), the thermocline shifted upward compared to the ARGO profiles. The root mean square error (RMSE) of the simulation

(a) Western BOB
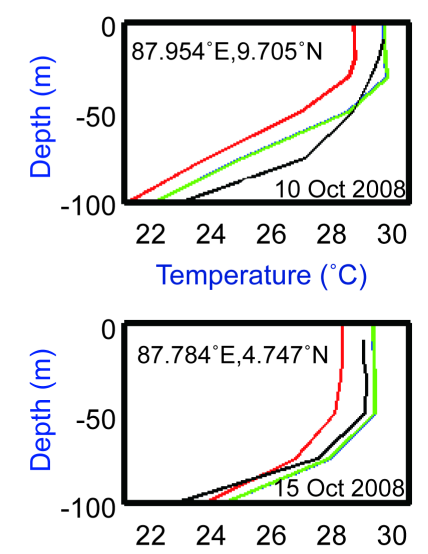

(c)
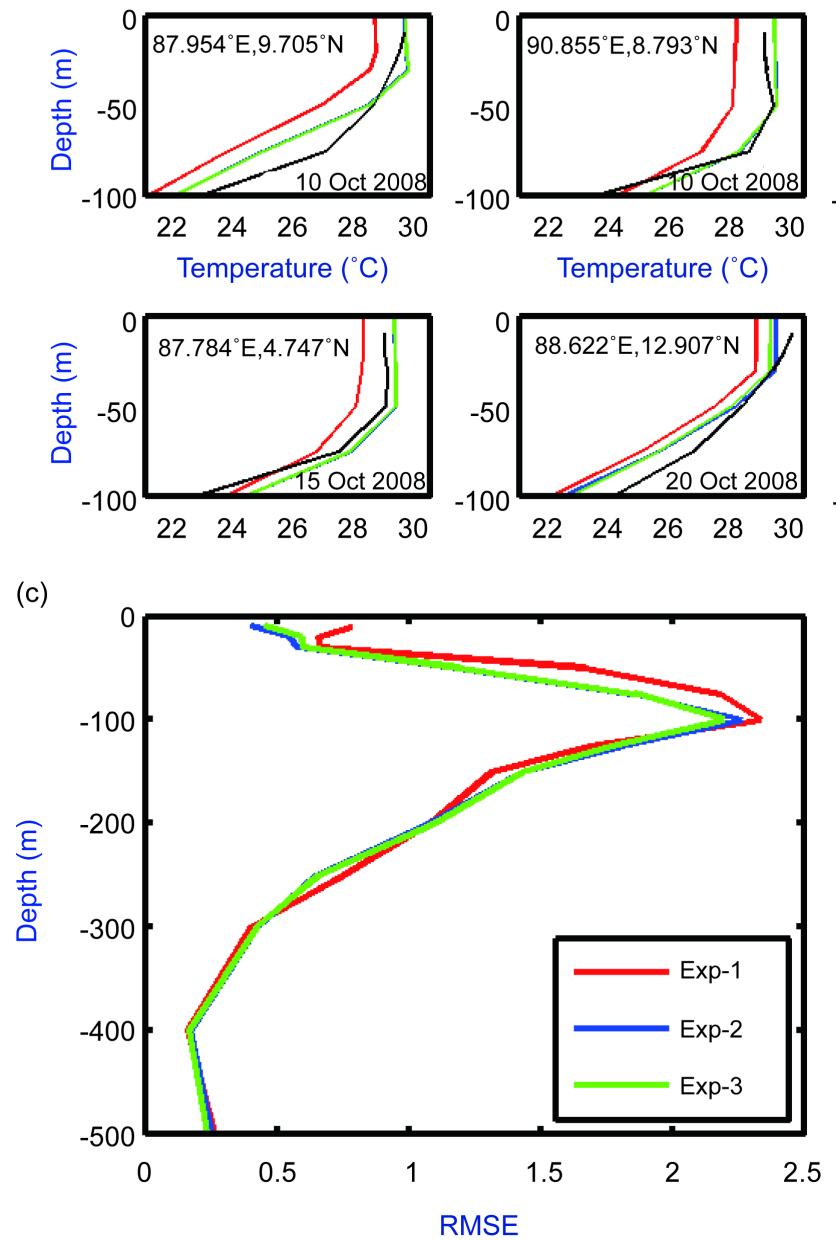

(b) Eastern BOB
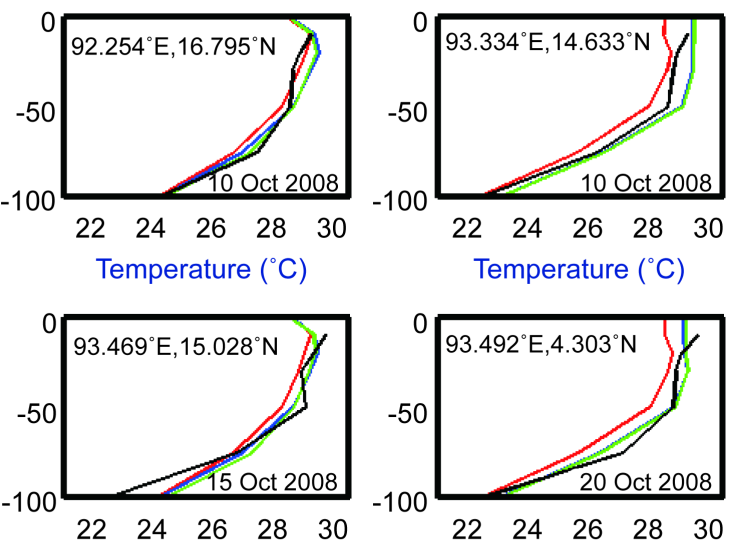

(d)

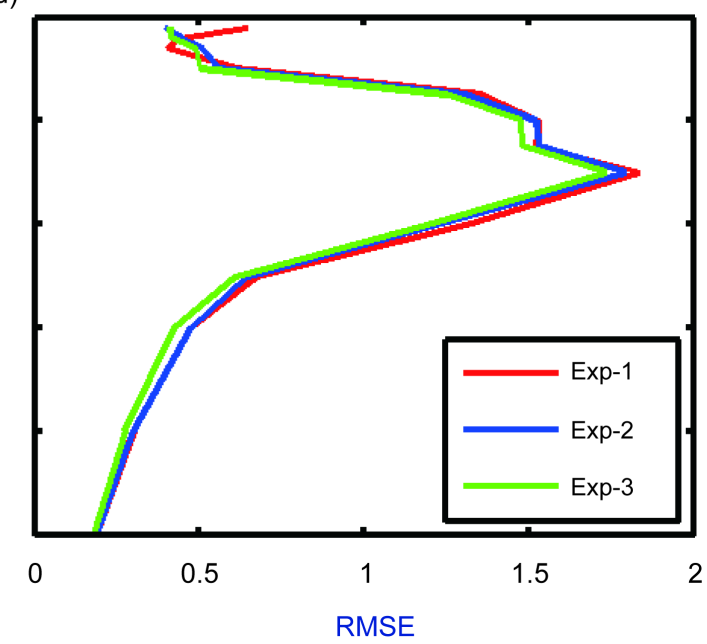

Figure 13. Vertical profiles at ARGO locations for October 2008 with the model experiments [Exp-1 (red), Exp-2 (blue), Exp-3 (green) and ARGO (black)] for (a) temperature of the western BOB, (b) temperature of the eastern BOB, (c) RMSE of the western BOB and (d) RMSE of the eastern BOB. 
experiments for the available profiles was calculated based on ARGO observations. These RSME vertical profiles for the simulation experiments (Exp-1, Exp-2 and Exp-3) for the western BOB and the eastern BOB are shown in Figure 13(c) and Figure 13(d), respectively. It was observed from these figures that Exp-2 was better than Exp-1, while Exp-3 was better than the other two experiments. In the thermocline zone, the errors were larger than those for the surface and bottom regions (Figure 13(c), Figure 13(d)). The overall error at the surface was approximately $0.5^{\circ} \mathrm{C}$, and in the deeper zone it was approximately $0.25^{\circ} \mathrm{C}$ for both the western (Figure 13(c)) and the eastern (Figure 13(d)) regions of the BOB. In the thermocline region, the error was between $0.5^{\circ} \mathrm{C}$ and $2.4^{\circ} \mathrm{C}$ for the western BOB (Figure $13(\mathrm{c})$ ) and between about $0.5^{\circ} \mathrm{C}$ and $1.8^{\circ} \mathrm{C}$ for the eastern BOB (Figure 13(d)). The percentage error at the surface, the thermocline zone and the deeper layer was about 1.6\%, $11 \%$ and $2 \%$, respectively, for the model experiments.

\subsubsection{Comparison with Drifters}

The model-simulated profiles were also compared between the two drifter locations that started on October 15 and 19, 2008 and days 20 and 24 of the model simulation (Figure 14(a), Figure 14(b)). We did not have drifters during the first week of simulation. The comparisons presented here are for the second and third week of the simulation, when the use of TMI and ARGO from October 4-6 was curtailed for days 19 - 30, when the drifters were collecting data. This leads to an insignificant difference between Exp-2 and Exp-3 for these days. Although the magnitudes were different for the simulation experiments compared to the drifters, the nature of the variations was well captured by the model. The difference was smallest for Exp-3 and largest for Exp-1, which indicates that the incorporation of ARGO and satellite data in the initial fields improved the model simulation results.

\section{Summary and Conclusions}

A high-resolution ocean multiscale prediction system was developed for the BOB region. The system first assimilates the in-situ observations and satellite observational data to create the synoptic initial fields in terms of the objective analysis (OA), and then the dynamical model of the ocean gives the ocean state forecast with the applied meteorological forcing. The climatology-based simulations using this high-resolution multiscale prediction
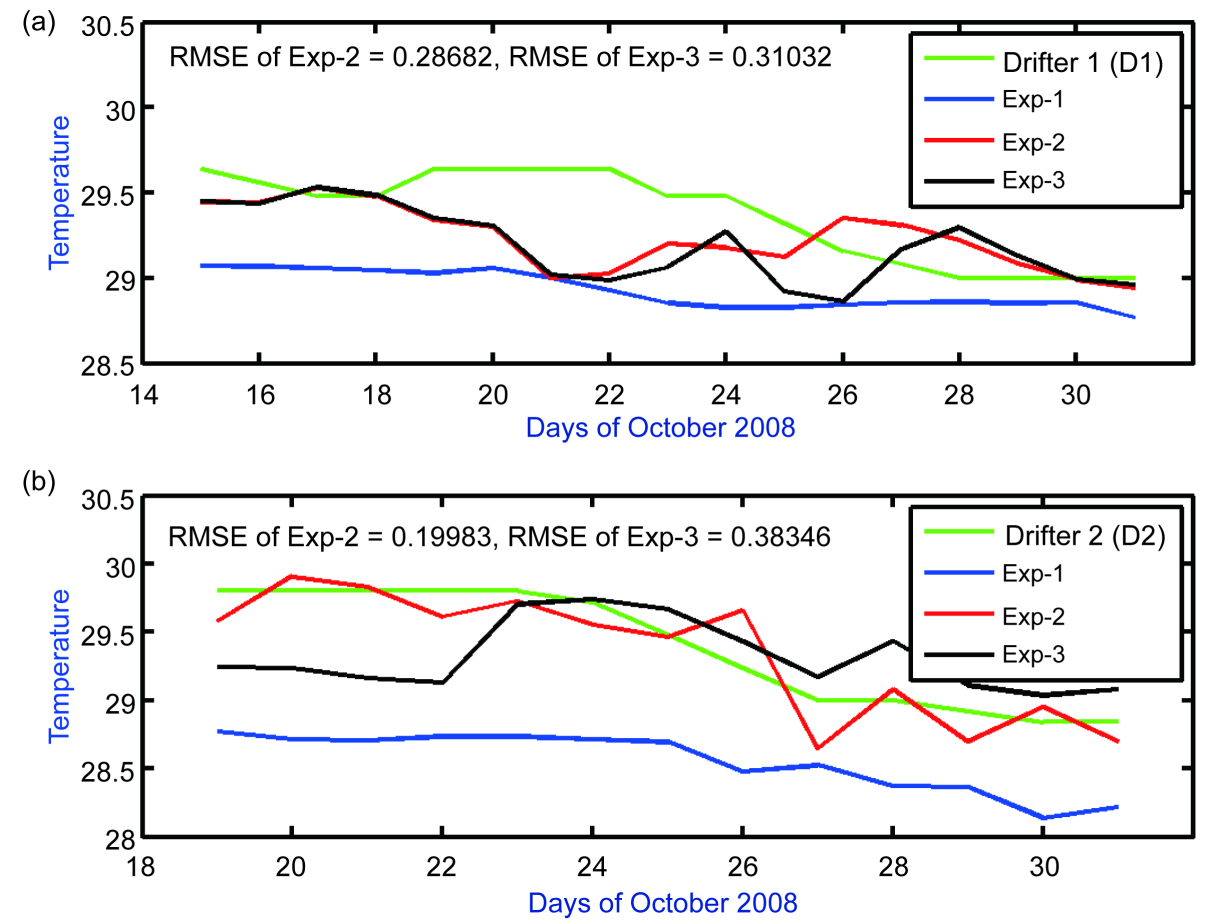

Figure 14. Validation of the sea surface temperature of the model experiments with (a) Drifter 1 (D1) and (b) Drifter 2 (D2). 


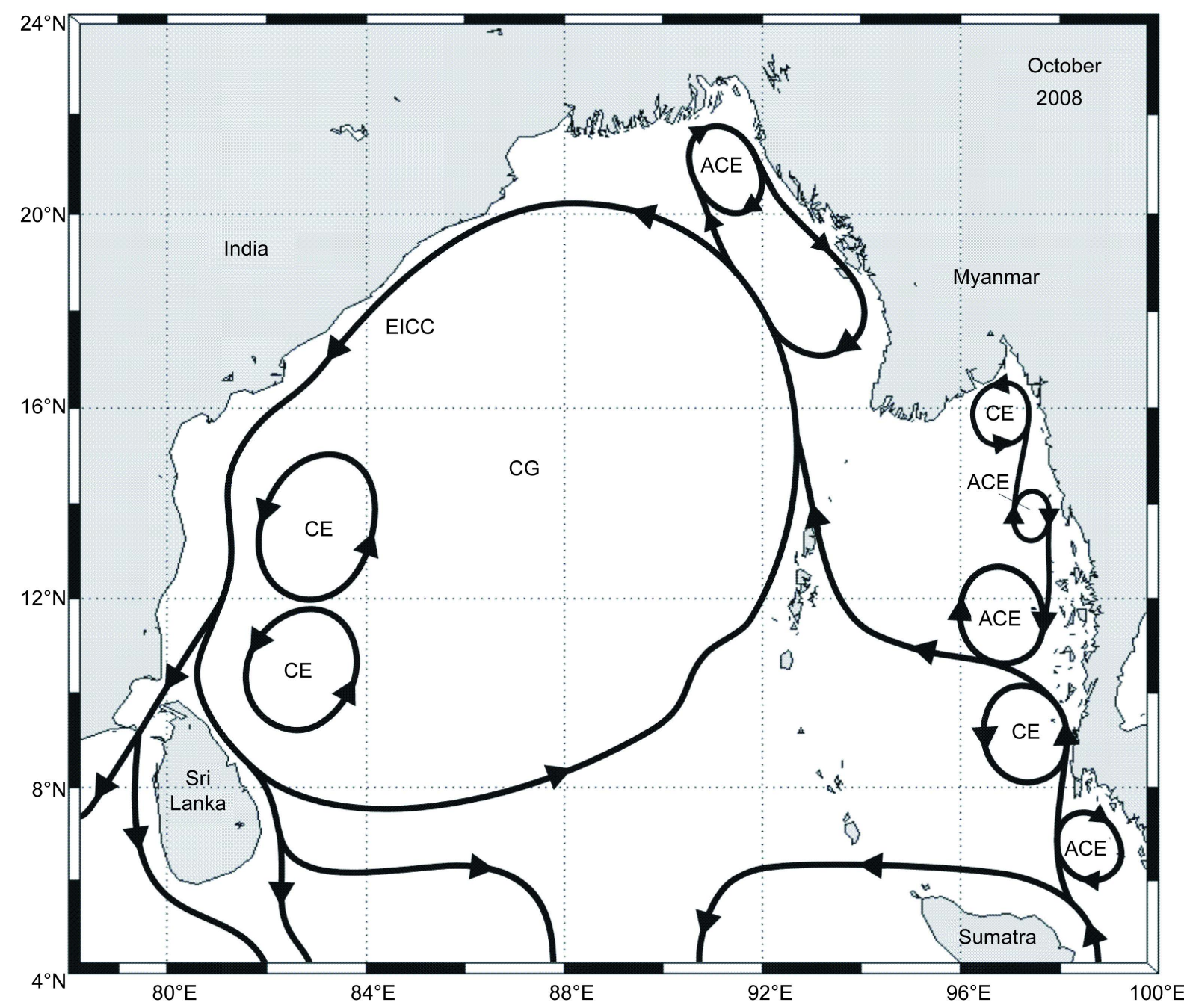

Figure 15. Schematic diagram of the BOB features during October 2008 from the model simulation. More features were observed on the eastern boundary during October 2008 compared to the climatological features seen in Figure 2.

system for the months of February, June and October demonstrated the capability of this system to produce the current climatological systems, gyres and mesoscale eddies, which are reported in Part I [3]. The model hindcasts for the month of October 2008 were verified here.

The inclusions of satellite data (TMI) and ARGO with TMI increased the magnitude of the boundary currents and clarified different mesoscale structures compared to the climatology-based simulations. At the surface, in addition to the EICC, basin-scale gyre, anticyclonic eddies $\left(91^{\circ} \mathrm{E}, 21^{\circ} \mathrm{N} ; 93^{\circ} \mathrm{E}, 18^{\circ} \mathrm{N} ; 97^{\circ} \mathrm{E}, 11^{\circ} \mathrm{N} ; 99^{\circ} \mathrm{E}, 6^{\circ} \mathrm{N}\right)$ and cyclonic eddies $\left(97^{\circ} \mathrm{E}, 16^{\circ} \mathrm{N} ; 95^{\circ} \mathrm{E}, 10^{\circ} \mathrm{N} ; 83^{\circ} \mathrm{E}, 11^{\circ} \mathrm{N} ; 83^{\circ} \mathrm{E}, 13^{\circ} \mathrm{N} ; 91^{\circ} \mathrm{E}, 12.5^{\circ} \mathrm{N} ; 97^{\circ} \mathrm{E}, 9^{\circ} \mathrm{N}\right)$ were observed in Exp-2 and Exp-3. Of these eddies, the cyclonic eddy at $97^{\circ} \mathrm{E}, 9^{\circ} \mathrm{N}$ and the anticyclonic eddies $\left(97^{\circ} \mathrm{E}, 11^{\circ} \mathrm{N} ; 99^{\circ} \mathrm{E}\right.$, $6^{\circ} \mathrm{N}$ ) were not simulated by the climatology-based simulation (Exp-1). At the subsurface, similar to the climatology-based simulation (Exp-1), the experiments with TMI and ARGO (Exp-2 and Exp-3) showed the westward intensification of the basin-scale cyclonic gyre. Cyclonic eddies $\left(86.5^{\circ} \mathrm{E}, 19^{\circ} \mathrm{N} ; 82.5^{\circ} \mathrm{E}, 14^{\circ} \mathrm{N} ; 79.5^{\circ} \mathrm{E}, 5^{\circ} \mathrm{N} ; 83^{\circ} \mathrm{E}\right.$, $\left.10^{\circ} \mathrm{N}\right)$ formed on the western side of the basin, and anticyclonic eddies $\left(97^{\circ} \mathrm{E}, 7^{\circ} \mathrm{N} ; 95^{\circ} \mathrm{E}, 12^{\circ} \mathrm{N} ; 91^{\circ} \mathrm{E}, 17^{\circ} \mathrm{N}\right)$ formed on the eastern side of the basin. Eddies were strong and distinct for Exp-2 and Exp-3. The cyclonic eddies at $93^{\circ} \mathrm{E}, 5^{\circ} \mathrm{N}$ and $97^{\circ} \mathrm{E}, 11^{\circ} \mathrm{N}$ were the extra features for Exp-2 and Exp-3 at the subsurface and were due to the impact of TMI and ARGO data. Thus, in-situ ARGO data and satellite observations can be used to create the synoptic initial fields, which in turn introduce extra features to the model simulation compared to the climatology-based initial condition simulation. 
The quantitative estimates of the volume transport in the upper $1000 \mathrm{~m}$ across different sections were comparable with observational studies. The model with ARGO profiles performed well for October 10, 15, and 20 of 2008, and almost all of the profiles were comparable with the observations. In the mixed layer, the model temperature was slightly lower (less than $0.4^{\circ} \mathrm{C}$ ) for several locations than it was in the ARGO profiles. The vertical profile of RMSE for Exp-3 was better than that in the Exp-2 and Exp-1 simulation experiments. In the thermocline zone, the errors were larger compared to those in the surface and bottom regions. The overall error was $\sim 0.5^{\circ} \mathrm{C}$ at the surface and $\sim 0.25^{\circ} \mathrm{C}$ in the deeper zone, but in the thermocline zone, it was slightly higher $\left(0.5^{\circ} \mathrm{C}<\right.$ RMSE $<2.4^{\circ} \mathrm{C}$ ) for the BOB. The percentage error at the surface was about $1.6 \%$; at the thermocline zone, it reached a maximum of $\sim 11 \%$ and in the deeper layer it was $\sim 2 \%$ for the model experiments.

The modeling system presented produced many mesoscale features that are not present in the climatologybased simulation due to the inclusion of satellite and in-situ observations at initialization. This is schematically captured and presented in Figure 15. The simulation of clear and distinct features as well as their proper placement at initialization provides a strong basis for utilizing this methodology for short-term prediction in this datasparse region. As presented here, and considered together with Part I of the climatology-based simulations, this modeling system is now ready to be used for semi-operational experimental forecasting with a week to two weeks of expected predictability.

\section{Acknowledgements}

The authors also gratefully acknowledge the financial support given by the Earth System Science Organization (ESSO) - Indian National Centre for Ocean Information Services (INCOIS), Ministry of Earth Sciences, and Government of India to conduct this research. We wish to thank Dr. M. Ravichandran and his group at INCOIS for making the TMI and ARGO data available for this project. We are thankful to Dr. Andre Schmidt, Dr. Ayan H. Chaudhuri and Ms. Carolina Nobre for their help and support during the study. We are also grateful to Mr. Frank Smith for his editorial help.

\section{References}

[1] Hedstorm, K.S. (1997) User's Manual for an S-Coordinate Primitive Equation Ocean Circulation Model (SCRUM) Version 3.0. Institute of Marine and Coastal Sciences, Rutgers University, 116 p.

[2] Haidvogel, D.B., Arango, H.G., Hedstrom, K., Beckmann, A., Malanotte-Rizzoli, P. and Shchepetkin, A.F. (2000) Model Evaluation Experiments in the North Atlantic Basin: Simulations in Nonlinear Terrain-Following Coordinates. Dynamics of Atmospheres and Oceans, 32, 239-281. http://dx.doi.org/10.1016/s0377-0265(00)00049-x

[3] Chakraborty, A. and Gangopadhyay, A. (2010) Development of a High-Resolution Multiscale Modeling and Prediction System for Bay of Bengal, Part I: Climatology Based Simulations. Journal of Atmospheric and Oceanic Technology. (Submitted)

[4] Stephens, C., Antonov, J.I., Boyer, T.P., Conkright, M.E., Locarnini, R.A., O’Brien, T.D. and Garcia, H.E. (2002) World Ocean Atlas 2001, Volume 1: Temperature. NOAA Atlas NESDIS 49, 167 p.

[5] Boyer, T.P., Stephens, C., Antonov, J.I., Conkright, M.E., Locarnini, R.A., O’Brien, T.D. and Garcia, H.E. (2002) World Ocean Atlas 2001 Volume 2: Salinity. In: Levitus, S., Ed., NOAA Atlas NESDIS 50, US Government Printing Office, Washington DC, 165 p.

[6] Cutler, A.N. and Swallow, J.C. (1984) Surface Currents of the Indian Ocean (to $25^{\circ} \mathrm{S}$ to $100^{\circ}$ E). Report No. 87. Institute of Oceanographic Sciences, Broadchill.

[7] Shetye, S.R., Gouveia, A.D., Shenoi, S.S.C., Shankar, D., Vinayachandran, P.N., Sundar, D., Michael, G.S. and Nampothiri, G. (1996) Hydrography and Circulation and Circulation in the Western Bay of Bengal during the Northeast Monsoon. Journal of Geophysical Research, 101, 14011-14025. http://dx.doi.org/10.1029/95JC03307

[8] Schott, F., Reppin, J. and Fischer, J. (1994) Currents and Transports of the Monsoon Current South of Sri Lanka. Journal of Geophysical Research, 99, 25127-25141. http://dx.doi.org/10.1029/94JC02216

[9] Jensen, T.G. (2001) Arabian Sea and Bay of Bengal Exchange of Salt and Tracers in an Ocean Model. Geophysical Research Letters, 28, 3967-3970. http://dx.doi.org/10.1029/2001GL013422

[10] Suryanarayana, A., Murty, V.S.N. and Rao, D.P. (1993) Hydrography and Circulation of the Bay of Bengal during Early Winter, 1983. Deep-Sea Research I, 40, 205-217. http://dx.doi.org/10.1016/0967-0637(93)90061-7

[11] Chan, P.K. and Gao, B.C. (2005) A Comparison of MODIS, NCEP, and TMI Sea Surface Temperature Datasets. IEEE Geoscience and Remote Sensing Letters, 2, 270-274. http://dx.doi.org/10.1109/LGRS.2005.846838 
[12] Carter, E.F. and Robinson, A.R. (1987) Analysis Models for the Estimation of Oceanic Fields. Journal of Atmospheric and Oceanic Technology, 4, 49-74. http://dx.doi.org/10.1175/1520-0426(1987)004<0049:AMFTEO>2.0.CO;2

[13] Lozano, C.J., Robinson, A.R., Arango, H.G., Gangopadhyay, A., Sloan, N.Q., Haley, P.J. and Leslie, W.G. (1996) An Interdisciplinary Ocean Prediction System: Assimilation Strategies and Structured Data Models. In: Malanotte-Rizzoli, P., Ed., Modern Approaches to Data Assimilation in Ocean Modelling, Elsevier Oceanography Series, Elsevier, Amsterdam, 413-452. http://dx.doi.org/10.1016/S0422-9894(96)80018-3

[14] Lermusiaux, P.F.J., Chiu, C.-S. and Robinson, A.R. (2001) Modeling Uncertainties in the Prediction of Acoustic Wave-Field in a Shelfbreak Environment. Proceedings of 5th International Conference on Theoretical and Computational Acoustics, Beijing, 21-25 May 2001.

[15] Ezer, T. and Mellor, G.L. (1997) Data Assimilation Experiments in the Gulf Stream Region: How Useful Are SatelliteDerived Surface Data for Nowcasting the Subsurface Fields? Journal of Atmospheric and Oceanic Technology, 14, 1379-1391. http://dx.doi.org/10.1175/1520-0426(1997)014<1379:daeitg>2.0.co;2

[16] Maltrud, E.M. and McClean, J. (2005) An Eddy Resolving Global 1/10 Ocean Simulation. Ocean Modelling, 8, 31-54. http://dx.doi.org/10.1016/j.ocemod.2003.12.001

[17] Calado, L., Gangopadhyay, A. and Silveria, I.C.A. (2008) Feature-Oriented Regional Modeling and Simulations (FORMS) for the Western South Atlantic: Southeastern Brazil Region. Ocean Modelling, 25, 48-64. http://dx.doi.org/10.1016/j.ocemod.2008.06.007

[18] Shaji, C. and Gangopadhyay, A. (2007) Synoptic Modeling of the West India Coastal Current System Using an Upwelling Feature Model. Continental Shelf Research, 24, 877-893.

[19] Kim, H.S., Gangopadhyay, A., Rosenfeld, L.K. and Bub, F.L. (2007) Developing a High-Resolution Climatology for the Central California Coastal Region. Continental Shelf Research, 27, 2135-2161.

[20] Varkey, M.J. (1986) Salt Balance and Mixing in the Bay of Bengal. PhD Thesis, University of Kerala, Trivandrum, $109 \mathrm{p}$.

[21] Rao, D.P. and Murty, V.S.N. (1992) Circulation and Geostrophic Transport in the Bay of Bengal. In: Swamy, G.N., Ed., Physical Processes in the Indian Seas (Proc. 1st Convention, ISPSO, 1990), NIO, Goa, India, 79-85.

[22] Sarkar, D., Chakraborty, A., Kumar, R. and Sharma, R. (2015) Retrieving of Temperature and Salinity of the interior Ocean from High Resolution Satellite Sea Surface Temperature. 4th National Conference of Ocean Society of India, 22-24 March 2015, CSIR-National Institute of Oceanography, Goa, India.

[23] Legeckis, R. (1987) Satellite Observations of a Western Boundary Current in the Bay of Bengal. Journal of Geophysical Research, 92, 12974-12978. http://dx.doi.org/10.1029/JC092iC12p12974

[24] Potemra, J.T., Luther, M.E. and O’Brien, J. (1991) The Seasonal Circulation of the Upper Ocean in the Bay of Bengal. Journal of Geophysical Research, 96, 12667-12683. http://dx.doi.org/10.1029/91JC01045

[25] McCreary, J.P., Han, W., Shankar, D. and Shetye, S.R. (1996) Dynamics of the East India Coastal Current. 2. Numerical Solutions. Journal of Geophysical Research, 101, 13993-14000. http://dx.doi.org/10.1029/96JC00560

[26] Paul, S., Chakraborty, A., Pandey, P.C., Basu, S., Satsangi, S.K. and Ravichandran, M. (2009) Numerical Simulation of Bay of Bengal Circulation Features from Ocean General Circulation Model. Marine Geodesy, 32, 1-18. http://dx.doi.org/10.1080/01490410802661930

[27] Babu, M.T., Sarma, Y.V.B., Murty, V.S.N. and Vethamony, P. (2003) On the Circulation in the Bay of Bengal during Northern Spring Inter-Monsoon (March-April 1987). Deep-Sea Research II, 50, 855-865. http://dx.doi.org/10.1016/S0967-0645(02)00609-4

[28] Gopalan, A.K.S., Gopala Krishna, V.V., Ali, M.M. and Sharma, R. (2000) Detection of Bay of Bengal Eddies from TOPEX and in Situ Observations. Journal of Marine Research, 58, 721-734. http://dx.doi.org/10.1357/002224000321358873

[29] Murukesh, N. (2007) Roles of Eddies in the Bay of Bengal Circulation Hydrography and in the Distribution of Nutrients and Chlorophyll. PhD Thesis, Goa University, National Institute of Oceanography, Goa. 